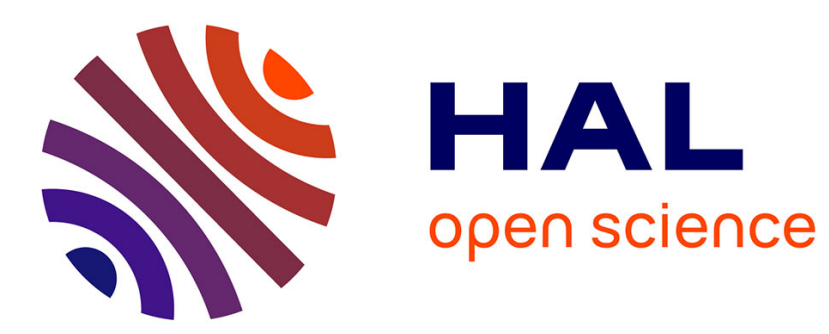

\title{
Grazing and the vanishing complexity of plant association networks in grasslands
}

Alexandre Génin, Thierry Dutoit, Alain Danet, Alice Le Priol, Sonia Kéfi

\section{To cite this version:}

Alexandre Génin, Thierry Dutoit, Alain Danet, Alice Le Priol, Sonia Kéfi. Grazing and the vanishing complexity of plant association networks in grasslands. Oikos, 2021, 130 (4), pp.541-552. 10.1111/oik.07850 . hal-03123198

\section{HAL Id: hal-03123198 https://hal.science/hal-03123198}

Submitted on 9 Mar 2021

HAL is a multi-disciplinary open access archive for the deposit and dissemination of scientific research documents, whether they are published or not. The documents may come from teaching and research institutions in France or abroad, or from public or private research centers.
L'archive ouverte pluridisciplinaire HAL, est destinée au dépôt et à la diffusion de documents scientifiques de niveau recherche, publiés ou non, émanant des établissements d'enseignement et de recherche français ou étrangers, des laboratoires publics ou privés. 
Grazing and the vanishing complexity of plant association networks in grasslands

\author{
Alexandre Génin ${ }^{1}$ \\ Thierry Dutoit ${ }^{2}$ \\ Alain Danet ${ }^{1,3}$ \\ Alice le Priol $^{1}$ \\ Sonia Kéfi ${ }^{1,4}$
}

1 ISEM, CNRS, Univ. Montpellier, IRD, EPHE, Montpellier, France

2 Avignon Université, Aix Marseille Univ, CNRS, IRD, IMBE, Avignon, France.

3 Centre d'Ecologie et des Sciences de la Conservation, CNRS, MNHN, Sorbonne Université, Paris, France.

4 Santa Fe Institute, 1399 Hyde Park Road, Santa Fe, NM 87501, USA 


\begin{abstract}
Interactions are key drivers of the functioning and fate of plant communities. A traditional way to measure them is to use pairwise experiments, but such experiments do not scale up to speciesrich communities. For those, using association networks based on spatial patterns may provide a more realistic approach. While this method has been successful in abiotically-stressed environments (alpine and arid ecosystems), it is unclear how well it generalizes to other types of environments.
\end{abstract}

We help fill this knowledge gap by documenting how the structure of plant communities changes in a Mediterranean dry grassland grazed by sheep using plant spatial association networks. We investigated how the structure of these networks changed with grazing intensity to show the effect of biotic disturbance on community structure.

We found that these grazed grassland communities were mostly dominated by negative associations, suggesting a dominance of interference over facilitation regardless of the disturbance level. The topology of the networks revealed that the number of associations were not evenly-distributed across species, but rather that a small subset of species established most negative associations under low grazing conditions. All these aspects of spatial organization vanished under high level of grazing as association networks became more similar to null expectations.

Our study shows that grazed herbaceous plant communities display a highly non-random organization that responds strongly to disturbance and can be measured through association networks. This approach thus appears insightful to test general hypotheses about plant communities, and in particular understand how anthropogenic perturbations affect the organization of ecological communities. 


\section{Keywords}

Plant-plant interactions, Grazing, Association networks, Ecological Networks, Spatial patterns, Co-occurrence 


\section{Acknoweldgements}

The authors warmly thank the staff from the Réserve Nationale des Coussouls de Crau for the numerous discussions and their help with logistics, with a specific thought to L. Tatin and A. Wolff. We also thank the members of the BioDICée team at ISEM along with J. Azuara and C. Kouchner for their help with field work, and D. Pavon (IMBE) for his help with plant identification. AG would like thank T. Daufresne, S. Boudsocq and J. Delarivière from Eco\&Sols (INRA) for their help with soil processing, sampling and survey design. The study has been supported by the TRY initiative on plant traits (http://www.try-db.org), maintained by J. Kattge and G. Bönisch (Max Planck Institute for Biogeochemistry, Jena, Germany), and supported by DIVERSITAS/Future Earth and the German Centre for Integrative Biodiv. Research (iDiv) Halle-Jena-Leipzig.

\section{Author contributions}

AG led conceptual framing, field work, data analyses and manuscript writing. AD and AlP helped with conceptual framing and field work. SK and TD provided significant support and advice all along the project. All authors contributed substantially to the manuscript writing and editing. 
Grazing and the vanishing complexity of plant association networks in grasslands

\section{Abstract}

Interactions are key drivers of the functioning and fate of plant communities. A traditional way to measure them is to use pairwise experiments, but such experiments do not scale up to species-rich communities. For those, using association networks based on spatial patterns may provide a more realistic approach. While this method has been successful in abiotically-stressed environments (alpine and arid ecosystems), it is unclear how well it generalizes to other types of environments.

We help fill this knowledge gap by documenting how the structure of plant communities changes in a Mediterranean dry grassland grazed by sheep using plant spatial association networks. We investigated how the structure of these networks changed with grazing intensity to show the effect of biotic disturbance on community structure.

We found that these grazed grassland communities were mostly dominated by negative associations, suggesting a dominance of interference over facilitation regardless of the disturbance level. The topology of the networks revealed that the number of associations were not evenly-distributed across species, but rather that a small subset of species established most negative associations under low grazing conditions. All these aspects of spatial organization vanished under high level of grazing as association networks became more similar to null expectations.

Our study shows that grazed herbaceous plant communities display a highly non-random organization that responds strongly to disturbance and can be measured through association networks. This approach thus appears insightful to test general hypotheses about plant communities, and in particular understand how anthropogenic perturbations affect the organization of ecological communities. 


\section{Introduction}

3 Ecological interactions are fundamental bricks of ecological communities and influence key properties

4 of ecological systems such as productivity, stability or response to perturbations (Tilman 1982,

5 Thebault and Fontaine 2010). This is in particular true of plant-plant interactions, which can determine

6 the fate of a given community following environmental perturbations (Verdú and Valiente-Banuet

7 2008). In some ecosystems, such as drylands (arid and semi-arid grasslands), certain "nurse” plant

8 species improve local environmental conditions around them, and thereby increase the recruitment,

9 growth and survival of other species below or close to their canopy (Callaway 2007). Such facilitative

10 interactions have been shown to influence how ecosystems respond to changes in temperature or biotic

11 stress (Kéfi et al. 2007). Understanding the effect of global changes in environmental conditions thus

12 requires knowledge on how those changes will affect species interactions.

14 A traditional approach to measure interactions between plant species is to use pairwise experiments

15 (Engel and Weltzin 2008). However, this can only work for a small set of species (Graff and Aguiar

16 2011, Holthuijzen and Veblen 2016), because the number of experiments required to measure

17 interactions among all the pairs of a diverse set of species is prohibitively high. In addition, pairwise

18 experiments do not always preserve the environmental setting of plant communities, so interactions

19 measured through experiments may be different from those that occur in situ (Engel and Weltzin

20 2008). For instance, this can happen because of indirect interactions (when an interaction between a

21 pair of species is altered by the presence of another; Wootton 1994, Levine et al. 2017). To overcome

22 this, recent work has sought to revisit an old approach (Vries 1954) and use the spatial associations of

23 pairs of species in a given community as proxies for their interactions (Saiz and Alados 2011). Put

24 intuitively, this approach is based on a principle of co-occurrence: individuals of species that facilitate 
each other are expected to be found next to each other more frequently than expected by chance (this is

26 referred to as a positive association hereafter). Conversely, individuals of species that have a net

27 negative interaction, i.e. exhibit interference with each other, should also exclude one another spatially

28 (hereafter, a negative association). Therefore, the way sessile species are spatially organized emerges

29 at least in part from species interactions. However, approaches attempting at recovering pairwise

30 species interactions from spatial associations have been shown to often fail (Freilich et al. 2018, Rajala

31 et al. 2019, Blanchet et al. 2020). This may be because intra-specific variability in interaction strengths

32 (Guimarães 2020), or confounding factors affect the patterns of spatial associations (e.g. shared habitat

33 preferences, D'Amen et al. 2018), but also because we often lack the statistical power to estimate with

34 precision the high number of pairwise associations in diverse communities (Rajala et al. 2019).

35 Nonetheless, recent research has shown that aggregated community-level properties such as the balance

36 between negative and positive interactions could be predicted with some accuracy using spatial

37 association patterns (Barner et al. 2018). The analysis of associations thus could, if not precisely

38 predict pairwise interactions, be a promising way of coarsely evaluating the general structure of

39 interaction networks in plant communities.

41 Another interesting aspect of the association approach is the use of networks. The structure of a

42 community as captured by pairwise associations can be represented as a network, where nodes are

43 species, and links represent the significant spatial associations between pairs of species. A sign can be

44 attributed to each link, either positive when two species tend to cluster in space (for positive

45 associations), or negative when they tend to segregate in space (for negative associations). The absence

46 of a link between two nodes in such network materializes the absence of any significant spatial

47 relationship between two species. Such signed networks are often referred to a "spatial association

48 networks" or simply "association networks" (used hereafter), as well as "spatial ecological networks"

49 (e.g. Saiz et al. 2018) or "co-occurrence networks" (Delalandre and Montesinos-Navarro 2018). 
50 Similar to food webs, they provide a unified way to describe the overall structure of a plant community.

51 For example, the importance of negative associations in a community is formally captured by the

52 proportion of negative links in its association network (the proportion of negative associations). The

53 topology of the networks (which species is linked to which) also provides essential information on

54 functioning: in a community, species that have many positive links with others could allow identifying

55 nurse species which facilitate many others; such presence of nurse species is expected to lead to a high

56 heterogeneity in the number of positive associations across species (Saiz et al. 2018). Conversely, in a

57 plant community where interactions are more symmetrical, such heterogeneity in the number of

58 significant associations per species should be lower. Association networks thus provide a rich

59 description of the structure of plant communities. Although they do not replace experimental

60 measurements of interactions, they provide a glimpse into the structure of communities, and an

61 opportunity to improve the current knowledge regarding the drivers of community functioning

62 (Losapio et al. 2019).

63

64 For many ecosystems, forecasting the upcoming ecological changes of the next decades requires

65 understanding how species interactions drive ecological dynamics. However, this is rendered difficult

66 by the fact that interactions themselves change with environmental conditions (e.g. precipitation,

67 Tielbörger and Kadmon 2000), abiotic stress levels (Callaway et al. 2002), or disturbance regimes (Saiz

68 and Alados 2012). Anticipating the upcoming changes in ecological systems, and plant communities in

69 particular, thus require the knowledge of how environmental conditions affect interactions, which can

70 be done by focusing on the way communities change along spatial gradients of increasing stress.

72 A major source of biotic stress in plant communities is grazing, which causes recurrent disturbance that

73 drives not only taxonomic and functional composition (Díaz et al. 2007), but also the structure of

74 species interactions. Grazing effects on association networks have mostly been studied in drylands so 
75 far, probably because of the striking spatial structure of the vegetation there, which is organized in 76 vegetation patches rather than homogeneously spread out in space (Verdú and Valiente-Banuet 2008).

77 This specific spatial structure arises from shrubs providing protection against grazing for other plants, 78 an interaction known as "associative protection". This mechanism has been extensively confirmed by 79 pairwise experiments outside our study area (Baraza et al. 2006, Graff et al. 2007, Graff and Aguiar 80 2011), and within it to some extent (Buisson et al. 2015). It has been shown to strongly influence the 81 structure of association networks by producing a unimodal pattern of variation of positive associations 82 along grazing gradients (Saiz and Alados 2012). Associative protection dominates at intermediate 83 levels of grazing, but is absent either when grazing is low and net negative interactions between 84 neighbours are most common (interference), or when grazing is very high, and disturbance is too high 85 for interactions to matter since grazers eat and trample the majority of the plant biomass. However, it is 86 unknown whether such mechanisms would be important enough to drive the structure of spatial 87 association networks in milder climates, and among herbaceous plants.

89 To help reduce this knowledge gap, we studied how grazing affected the topology of plant association 90 networks in a Mediterranean grassland. Contrasting with previous studies, our work focuses on the 91 variations of associations in fully-herbaceous communities without shrubs, more constrained by 92 grazing, less by climate, and with a majority of annuals, which have often been ignored in association 93 studies (e.g. Soliveres and Maestre 2014). We investigated the effect of sheep pressure on several key 94 structural aspects of association networks that have been shown to vary in previous studies (Saiz and 95 Alados 2012, Saiz et al. 2018) : (i) the total number of associations (i.e. whether plant communities are 96 strongly spatially-structured by associations); (ii) the importance of positive and negative associations 97 and (iii) the heterogeneity of association networks (i.e. a measure of the variability of the number of 98 associations across species; Saiz et al. 2018). Based on seminal hypotheses regarding plant interactions, 99 we hypothesized the following regarding the trends in the proportion of association types along the 
100 grazing gradient:

101

102 H1. at low grazing pressure, interference between plant species dominates and the number of

103 negative associations is therefore at its maximum along the gradient (Michalet et al. 2006):

$104 \quad \mathrm{H} 2$. at intermediate grazing pressure, positive associations should be at their maximum due

105 to the possible presence of associative protection (Maestre et al. 2009, Smit et al. 2009)

106 H3. at high grazing pressures, where biotic disturbance levels are the highest, both negative 107 and positive interactions should have a low impact on spatial structure, and thus there should be fewer

108 significant plant associations, both negative and positive (Graff and Aguiar 2011)

109

110 After testing these hypotheses and describing the changes in the structure of the association networks,

111 we discuss how these can be used to improve the assessment of plant community structure.

112

113 


\section{Methods}

\section{Sampling site}

116

117 We carried out this work in a Mediterranean dry grassland located in the south of France, La Crau

118 (longitude $4.882 \mathrm{E}$; latitude $43.548 \mathrm{~N}$ ), where vegetation has been grazed by sheep for at least 2000

119 years (Badan et al. 1995). Plant communities are diverse and mostly composed of herbaceous plants

120 (on average $30 \pm 12$ species/ $\mathrm{m}^{2}$ in this study, mean \pm s.d.), with very few perennial higher shrubs,

121 leading to an outstanding steppe-like landscape. Grazing in La Crau is intense relative to other systems

122 and has been centered around numerous sheepfolds for centuries (Saatkamp et al. 2020), around which

123 ruderal nitrophilous species dominate as a response to the high grazing and trampling pressure and soil

124 nutrient levels (Figure (Devaux et al. 1983). Further from sheepfolds, typical dominant species include

125 Brachypodium retusum P. Beauv. with interspersed Thymus vulgaris L. and Asphodelus ayardii

126 Jahand. \& Maire (Molinier and Tallon 1950, Buisson and Dutoit 2006). This very-well defined

127 gradient constitutes an ideal "natural experiment" setting, as around sheepfold the effects of grazing

128 pressure strongly dominate over other environmental characteristics (Figure 1 and Supplementary

129 Information 1).

\section{Surveys}

132 We selected six sites, i.e. six sheepfolds, spread out in the study area of 10500 ha of a steppe-like 133 ecosystem (Buisson and Dutoit 2006). Surveys were carried out during the plant growing season (Apr

13415 - June 10), which is the time of the year where approximately $80 \%$ of the species can be detected

135 and identified. This was done during the years 2016 and 2017. The survey period was comprised within

136 the grazing season, which is from February to June. 
138 Computing species spatial associations requires characterizing the spatial structure of plant

139 communities, which we did using pairs of 5-meter long transects. The grazing gradient is known to

140 produce a change in vegetation composition, which has been classified into successive types that form

141 "belts" around a given sheepfold (Molinier and Tallon 1950, Buisson and Dutoit 2006). Around the

142 sheepfold, species that are most nitrophilous or grazing-resistant predominate, such as Urtica sp. and

143 Onopordum illyricum L. (Figure 1a, red and yellow areas). Moving away from the sheepfold, these are

144 replaced by plant assemblages in which Trifolium spp. dominates (Figure 1a, green areas), until the last

145 type of community is reached, with high covers of Brachypodium retusum (Figure 1a, white dashed

146 areas; Supplementary Information 1). This latter type constitutes most of the vegetation in the study

147 area and represents communities where grazing pressure is at its lowest. We identified each belt in

148 space based on a preliminary quadrat-based survey, and placed the transects in the different vegetation

149 belts to document a wide range of grazing levels (Supplementary Information 1). We laid out two

150 replicate transects in each belt, separated from at least $10 \mathrm{~m}$ but no more than $75 \mathrm{~m}$ so that we could

151 consider that the two transects were under similar levels of grazing pressure. The starting point and

152 direction of each transects were chosen randomly by throwing a pen. To make sure that no

153 environmental factor would affect spatial associations (e.g. two species co-occurring because they

154 share a similar microhabitat), we repeated the throw whenever the environmental conditions appeared

155 to vary along a transect (e.g. when vehicle tracks, water puddle, ant nest or any other visible

156 heterogeneity was present). For each transect, we laid out a measuring tape, and recorded the length

157 over which every part of plant individuals overlapped (Figure 2). Individual positions could be

158 determined with an accuracy of $2 \mathrm{~mm}$, as estimated from repeated measurements: this very fine spatial

159 grain was chosen to allow the detection of positive and negative associations alike (Araújo and

160 Rozenfeld 2014) as it was close to the typical length over which plants intersected the transect (2 to 3

$161 \mathrm{~mm})$. At some sites, some intermediate vegetation belts were absent or not identifiable in the field and 
162 were therefore not sampled. As a result, one site had two missing belts (i.e. two pairs of transects), and

163 two others had one belt missing (i.e. one pair of transects). In two sites, we carried out the sampling

164 both in 2016 and 2017 to increase our sample size, yielding a final dataset with 2 to 8 pairs of transects

165 per site.

\section{Measuring species associations}

167 Our statistical analyses comprised two broad steps. First, we computed the association networks (one

168 association network for each pair of transects) and summarized them into community-level metrics

169 (e.g. the total number of negative links). Then, we investigated how these community-level metrics

170 changed along the grazing gradient.

171

172 Computing networks and community-level metrics

173 Computing association networks can be done by defining a metric of association between two species,

174 and assigning a positive (resp. negative) link when the metric for the pair of species is above (resp.

175 below) a reference threshold (Sanderson and Pimm 2015). Here, we used the total overlap between

176 individuals of a pair of species to measure pairwise association (this is equivalent to using the number

177 of co-occurrence when using discrete sampling). In more formal terms, for a given species $i$

178 intersecting $n$ times in a transect, and a species $j$ intersecting $m$ times, the total overlap $O_{i j}$ within a

179 transect is computed as follows:

$$
O_{i j}=\sum_{l=1}^{n} \sum_{k=1}^{m} \int_{x=0}^{x=L} I_{l k}(x) d x
$$

181 where $L$ is the length of the transect and $I_{l k}(\mathrm{x})$ is equal to 1 when both individual $l$ and $k$ are present at

182 position $x$ along the transect, and 0 elsewhere (Figure 2). As we sampled two transects per vegetation

183 belt, which can be considered as replicates, we computed $O_{i j}$ for both transects, and used their total as

184 the metric of association between pairs of species. It is worth noting that $O_{i j}=O_{j i}$ for any $i$ and $j$, so 
associations are symmetric.

186 For each pair of species, the above procedure yields an observed value of total overlap. It remains to be 187 determined whether this value is significantly high or low, i.e. whether species significantly cluster or 188 segregate in space. To do so we used a randomization-based approach that compared the observed 189 patterns to that of a null expectation with the same total cover for each species, but random spatial structure. We took the observed pair of replicate transects and randomized the position of each segment 191 over which plant individuals intersected the transect (one rectangle in Figure 2b). We did so by placing 192 all segments at a new, random position in the pair of replicate transects (a given individual segment 193 could thus occur in one of the two replicate transects, but be in the other one after randomization). New 194 random positions were redrawn if necessary so that no segment in the random transects would extend 195 past the last segment in the observed transects. Put graphically, no segment would be placed past the 196 rightmost rectangle in Figure 2b. We generated 1999 pairs of such random transects, and recomputed 197 the total overlap $O_{i j}$ between each species, thus obtaining a null distribution of total overlap for each 198 species pair. Pairwise associations were then classified into positive, negative or neutral by using a 199 cutoff value $\alpha$ applied to the null distribution. A positive association was considered to occur between 200 a pair of species when $1-\alpha / 2 \%$ of the null distribution was below the observed value. Conversely, a 201 negative association was retained when $\alpha / 2 \%$ of the null distribution was above the observed value. 202 We used a threshold of $25 \%$ (i.e. $\alpha=0.25$ ), so for example a positive association was retained when 203 the observed overlap was above $87.5 \%$ of the null distribution. The value of $\alpha$ represents a tradeoff 204 lower values produce association networks in which species exhibit strong spatial patterns (spatial 205 aggregation or segregation), but the resulting networks have very few links, so community-level 206 metrics may be unreliable. As the choice of such cutoff value may affect the results, we carried out a 207 sensitivity analysis to make sure that the results were robust to a range of thresholds (Supplementary 208 Information 3). 
210 For each pair of transects, this first step of the analysis yields a set of $A^{+}$significant positive and $A^{-}$ 211 significant negative associations. This set can be thought as a network where nodes constitute species 212 and positive and negative associations are positive or negative links between them (Figure 1, b1). We 213 summarized these networks into six community-level metrics:

$214 \quad K^{+}$, and $K^{-}$, the fraction of positive and negative links in the network, computed respectively 215 as $A^{+} / A_{\max }$ and $A^{-} / A_{\max }$, where $A_{\max }$ is the maximum possible number of links, $S(S-1) / 2$ 216 for an undirected network with S species and no self-interaction

217 - L the total fraction of links computed as $\left(K^{+}+K^{-}\right)$, which measures the density of links in the 218 association network, and thus the general importance of associations on community structure

$219 \quad R$, the ratio of positive to negative links, defined as $\left(K^{+}-K^{-}\right) /\left(K^{+}+K^{-}\right)$(Díaz-Sierra et al. $220 \quad$ 2017)

- $H^{+}$and $H^{-}$, measuring the heterogeneity of associations, as defined in Estrada 2010. This index captures how close a network is to a star-graph, i.e. whether only one outlying species establishes all links (maximum index value of one), or whether all species have the same number of links (minimum value of zero). Such index is well-suited to assess heterogeneity in small networks for which distribution-fitting is unreliable (Estrada 2010). This index is computed as follow: where the sum is done over the set of all edges in the network $E$. $i$ and $j$ describe the nodes involved in an edge, with their corresponding degrees $k_{i}$ and $k_{j} . N$ here is the total number of nodes with degree non-zero (i.e. that have at least one link). We computed this metric on networks made up only of positive links (for positive associations) or negative links (for 

negative associations), which yielded $\mathrm{H}^{+}$and $\mathrm{H}^{-}$.

\section{Cover-corrected community-level metrics}

234 Despite being taken into account in the null model to derive pairwise associations, species covers still

235 have an effect on the community-level metrics defined above. To illustrate this, we can consider the

236 example of rare species. By definition, pairs of rare species have low covers, hence placing them

237 randomly in a transect will yield a null distribution of overlap mostly composed of zeroes. Because the 238 overlap cannot be negative, such species pair cannot have an observed overlap below the random 239 expectation, i.e. a negative association. As a result, as the number of rare species changes along a 240 gradient, the proportion of negative associations $\left(K^{-}\right)$will vary, masking the biologically-relevant 241 changes in the spatial behavior of species. A similar dependence on species' cover distribution affects 242 all community-level metrics $\left(L, K^{+}, K^{-}, R, H^{+}\right.$, and $\left.H^{-}\right)$, so it is necessary to control for this effect to 243 make meaningful statements about changes in plant associations along a gradient (Tylianakis and 244 Morris 2017, Pellissier et al. 2018, Saiz et al. 2018). This bias is further detailed in the Supplementary 245 Information 4.

247 We corrected community-level metrics using the following procedure (Figure 1b). For each pair of 248 transects, we created 999 'null' pairs, with randomized positions of individuals (mixing individuals 249 between transects, i.e. carrying the same randomization as in the first step of the analysis). We built 250 association networks using the same procedure, this time starting with the randomized pairs of 251 transects. For each pair of replicate transect, we obtained this way 999 association networks that 252 represent the null expectation of random spatial structure, but similar species total covers. We then 253 computed the community-level metrics on the null networks to obtain, for each pair of replicate 254 transects, 999 null values for each metric. For example, we obtained null values for $K^{-}$(the proportion 255 of negative associations) for each pair of replicate transects. We then computed the deviation of the 
observed value to its null distribution, using a z-score (or standardized effect size, SES; following

257 example given for $K^{-}$):

$$
K_{S E S}^{-}=\left(K^{-}-\mu_{\text {null }}\right) / \sigma_{\text {null }}
$$

259 where $\mu_{\text {null }}$ is the mean of the null distribution for the community-level metric, and $\sigma_{\text {null }}$ is its standard

260 deviation Figure 1, b3). 999 null replicates were considered enough to estimate with reasonable

261 precision these two parameters. By focusing on the changes in this z-score instead of the raw value of 262 each community-level metric, we measured the changes in a given aspect of the association network,

263 controlling for the effect of changing species covers along the gradient (Tylianakis and Morris 2017,

264 Pellissier et al. 2018).

\section{Characterizing the grazing gradient}

267 In La Crau, the local grazing pressure (the number of sheep*time unit.ha ${ }^{-1}$ ) is known to decrease with 268 the distance to the sheepfold, but this relationship has not been explicitly measured for most sites.

269 Previous studies (Dureau 1998; Supplementary Information 2) suggest that it decreases as the inverse 270 of distance then reaches a minimum, i.e. that grazing pressure $G$ can be described by the following 271 function:

$$
G(x)=G_{\text {inf }}+\frac{G_{0}-G_{\text {inf }}}{1+\tau x}=\frac{\tau G_{0}+x G_{\text {inf }}}{\tau+x}(\text { equation } 1)
$$

273 where $x$ is the distance to the sheepfold, $G_{\text {inf }}$ is the grazing pressure far from the sheepfold, $G_{0}$ is the 274 grazing pressure at the sheepfold, and $\tau$ characterizes the spatial extent of the gradient.

276 Soil characteristics are expected to follow closely the grazing pressure. This is particularly true for soil

277 nutrients that are spatially redistributed as grazers feed in a given area and defecate in another

278 (Steinauer and Collins 1995, Selbie et al. 2015). In our area, we thus expected the variations in the 279 amount of nutrients in the soil to closely match those in grazing pressure. We therefore carried out 
sampling to measure soil properties as a function of the distance to the sheepfold. We sampled soil

281 wherever a pair of transects was carried out, and complemented these samples with additional ones

282 where the grazing gradient was very extended (see Supplementary Information 1). Soil was sampled by

283 mixing subsamples of the upper first five centimeters (after scraping sheep dung) from a circular area

284 of radius $4 \mathrm{~m}$. Soil sampling took place in October 2017, when sheep flocks were absent.

286 We used the total Nitrogen content $\left(N_{\text {tot }}\right)$ in the soil (as measured by the Kjeldahl method; Bremner 287 1960) to characterize the grazing pressure at a given distance from the sheepfold. We assumed that the 288 total $N$ measured from soil samples was linearly-related to the (unmeasured) grazing pressure, i.e. that $289 N_{\text {tot }}=a G(x)+b$ (with $a$ and $b$ being the slope and the intercept, respectively). Based on equation 1, 290 this yields the expected relationship between distance $x$ and nitrogen content $N_{\text {tot }}$, which we fitted to 291 the empirical data:

$$
N_{t o t}(x)=\frac{\tau N_{t o t, 0}+x N_{t o t, i n f}}{\tau+x}(\text { equation } 2)
$$

293 Because we had a reduced number of samples per site (2 to 4) and standard non-linear regression was 294 prone to overfitting, we carried out the regression using a Bayesian setting and weakly conservative 295 priors. We used the site as a random effect on the estimates of $\tau, N_{\text {tot }, 0}$ and $N_{\text {tot,inf }}$ along with a

296 Gaussian residual error (see Supplementary Information 2 for details on parameter estimation).

297 We checked that the estimated values for $N_{\text {tot, } 0}$ and $N_{\text {tot,inf }}$ were consistent with previous reported 298 values for the area (Römermann et al. 2005), and then used the estimated $N_{\text {tot }}$ in the soil at the given 299 distance to the sheepfold as a proxy for grazing pressure.

\section{Effect of grazing pressure on associations}


303 We characterized the effect of grazing on species associations by investigating the trends of

304 community-level metrics along the gradient of grazing pressure (as measured by $N_{\text {tot }}$ ). To test whether

305 the trends were linear or unimodal (hump-shaped), we fitted both a straight-slope and a second-order

306 polynomial model, with the focal metric as response (e.g. $R_{S E S}$ ), the estimated $N_{t o t}$ as predictor and the

307 site as a random effect on the trend coefficients. We carried out this regression using a Bayesian setting

308 with uninformative priors, and retained the model that had the lowest error when carrying leave-one-

309 out (loo) cross-validation, following recommendations from Vehtari et al. (2017). We used normal

310 priors with mean zero and standard deviation 50 for regression coefficients, and an exponential prior

311 with rate 0.1 for the residual error parameter.

312

313 All analyses were carried out in R v4.0.2 (R Core Team 2020), with regressions carried out using the

314 package loo v2.3.1 (Vehtari et al. 2017) and brms v2.14.0 (Bürkner 2017). Data and code used for the

315 analyses are available at https://datadryad.org/stash/dataset/doi:10.5061/dryad.ns1rn8prd [private

316 during peer-review]. Trait data to compute the percentage of ruderal species was obtained from the

317 TRY database (Kühn et al. 2004, Kattge et al. 2020). 


\section{Results}

320 We found that the grazing gradient around sheepfolds had a strong effect on soil conditions, as total

321 nitrogen of the soil was doubled (model estimation of $1.35 \pm 0.36 \mathrm{~g}^{\mathrm{kg}} \mathrm{kg}^{-1}$ far from sheepfolds vs.

$3222.85 \pm 0.27$ g. $\mathrm{kg}^{-1}$ at the entrance; Figure 3a). Such values are consistent with what has been previously

323 reported in the study area (Römermann et al. 2005, Saatkamp et al. 2020). The effects of grazing on

324 soil surface conditions were evidenced by the increase in bare ground from $20 \pm 7 \%$ to $42 \pm 14 \%$

325 (Figure 3b) and dung cover from $9 \pm 5 \%$ to $92 \pm 12 \%$ (Figure 3c). Grazing favored higher covers of

326 ruderal species $(17 \pm 8 \%$ to $63 \pm 5 \%$, Figure $3 \mathrm{~d})$ and reduced species richness $(49 \pm 6$ species far, vs

$32710 \pm 1$ close to sheepfolds; Figure 3e).

329 Regarding plant association metrics, model selection favored linear relationships (straight lines) for all

330 relationships between association-based community-level metrics and grazing pressure (Figure 4,5). In

331 particular, we found no support for unimodal variations of the number of positive associations $K_{S E S}^{+}$

332 along the gradient (Figure 4c).

334 Grazing was found to increase the number of links in plant communities (LSES, Figure 4a), as positive 335 associations decayed quicker than negative associations with grazing (Figure 4b, 4c). Overall, there

336 was an excess of negative associations compared to positive associations $\left(K_{S E S}^{-}\right.$was always above zero

337 and $K_{S E S}^{+}$almost always below zero; Figure $\left.4 \mathrm{~b}, 4 \mathrm{c}\right)$. Both negative and positive associations were found 338 to approach the null expectation (i.e. a value of $K_{S E S}^{-}$and $K_{S E S}^{+}$close to zero) as sheep pressure

339 increased (Figure 4b, 4c). Consistent with these patterns, the association ratio $R_{S E S}$ was always

340 negative regardless of the grazing level, and close to the null expectation where grazing was the highest

341 (Figure 4d). This suggests that these communities were strongly structured by spatial associations at

342 low grazing pressure, but became increasingly close to the null expectation with increased grazing. 
344 The heterogeneity in negative associations $H_{S E S}^{-}$decreased with grazing pressure (Figure 5a). In other

345 words, plant species of a given community had similar numbers of negative associations with each

346 other under high grazing conditions and more variable ones under low grazing. We found no equivalent

347 effect of grazing on the heterogeneity of positive associations $H_{S E S}^{+}$(Figure 5b).

348

349 All the above trends were robust to the choice of $\alpha$ (Supplementary Information 3 ).

350

351

352 


\section{Discussion}

354 Using continuous transects documenting the spatial associations of plant individuals in a Mediterranean

355 dry grassland, we found non-random trends in spatial associations along the grazing intensity gradient.

356 Negative associations were found to dominate over positive ones under low grazing, with a highly-

357 variable number of negative association per species. Grazing was found to reduce all these

358 characteristics to their null expectations, overall making the communities less structured by

359 interspecific associations at high grazing levels.

\section{Association trends}

\section{Changes in association trends}

363 We found that negative associations dominated where grazing pressure was lower (H1), which is

364 consistent with interference driving the assembly of communities (Graff et al. 2007). As grazing

365 pressure increases, it appears that this imprint of interference on spatial patterns vanishes. This is

366 consistent with the known effects of grazing in grasslands: as biomass is removed from dominant

367 species, ground-level light increases and thus spatial exclusion by taller competitors is reduced (Borer

368 et al. 2014, Odriozola et al. 2017). However, such decrease in negative interactions is usually

369 associated with an increase in species richness that we did not observe here (Figure 3e). This suggests

370 that the trends observed here reflect more than a sole reduction in interference. Given the very high

371 disturbance levels around sheepfolds (more than 1000 sheep being present daily close to sheepfolds),

372 another factor altering spatial patterns is the direct reduction in covers due to the sheep presence (Adler

373 et al. 2001, Graff and Aguiar 2011). Disturbance may be too high to allow plants to grow enough

374 during the grazing season to preempt space and produce significant spatial patterns (Alados et al.

375 2004). Disentangling this direct effect of disturbance on spatial associations from that of the processes

376 occurring within the plant community would require additional independent evidence, and constitutes a 
377 limit of relying only on association networks.

379 Positive associations exhibited no unimodal trend along the grazing gradient $(\mathrm{H} 2)$. Instead, we found

380 that they declined linearly with increasing grazing. This contrasts with previous work reporting

381 unimodal trends along grazing gradients both experimentally (Smit et al. 2009) and using association

382 (Saiz and Alados 2012, Le Bagousse-Pinguet et al. 2012). A possible explanation for this pattern is that

383 our study was carried out in areas where the grazing pressure is always relatively high compared to

384 other work using association networks. Stocking rates in La Crau often reach above 1 ind.ha ${ }^{-1}$ (Buisson

385 et al. 2015), well above the maximum rate of 0.64 ind.ha ${ }^{-1}$ reported by Saiz et al. (2012). It is thus

386 likely that we could only document the reduction in the importance of interactions under high

387 disturbance, as suggested by Graff et al. (2013). Moreover, positive associations were found to be less

388 frequent than expected by chance at all grazing levels, suggesting that facilitation is rare in our system.

389 This general absence of facilitation, despite some existing experimental evidence (Buisson et al. 2015),

390 could emerge from the particular morphology of the plants in the study area. The study area lacks tall

391 woody shrubs which are a major source of positive associations, as they often act as nurse species

392 under which herbaceous plants grow in dry areas (Saiz and Alados 2012). Compared to the study of

393 Saiz and Alados (2012), at our sites, plants are more functionally similar (forbs and grasses of similar

394 heights), which limits the possibility of plants to aggregate in space by growing on top of, or below,

395 each other, and thus the proportion of positive associations. This could explain in particular why the

396 species Brachypodium retusum, which exhibits mostly negative associations in our work, was found to

397 engage mostly in positive ones in Saiz and Alados (2012). By reducing the necessary complementarity

398 in height and morphology of the plants for spatial aggregation, i.e. increasing functional similarity,

399 grazing could reduce the prevalence of positive associations in our study area. 
402 While plant ecology has mostly focused on describing the relative importance of different types of

403 interactions (e.g. the relative importance of facilitation vs. interference; Callaway et al. 2002, Michalet

404 et al. 2006, Soliveres et al. 2015), it has seldom focused on the structural aspects of plant-plant

405 interaction networks. For example, facilitation in abiotically-stressed environments can be asymmetric,

406 with key nurse plants facilitating many others, or more symmetric, where plants with similar lifeforms

407 buffer each other against harsh conditions (Lin et al. 2012). In our study, such asymmetry was found in

408 negative associations. We found that they were more heterogeneous when grazing was low. This

409 suggests that under low grazing conditions, inter-specific interference is asymmetric, with few species

410 establishing a high number of negative links, and does not arise from all plants being equally more

411 competitive. This maps well onto limiting-similarity acting where competition for resources dominates

412 (Chesson 2000), which favors functional divergence in traits (Valiente-Banuet and Verdú 2008) and

413 plant strategies. Some plants may engage in "Competitive confrontation" (sensu Novoplansky 2009) by

414 maximizing interference with their neighbors, while other may display "Competitive avoidance" or

415 tolerance and avoid such behavior (Gruntman et al. 2017). This diversity in plant strategies may be a

416 factor explaining the heterogeneity in negative links. As grazing increases, communities converge

417 towards grazing-tolerant strategies (Carmona et al. 2012 and Figure 3d), resulting in the observed

418 reduction of network heterogeneity. Such hypotheses could be tested with theoretical models exploring

419 the link between plant traits and strategies, and the structure of interaction networks in plant

420 communities. More generally, this line of thought could also be extended to other network properties

421 such as modularity, nestedness (Verdú and Valiente-Banuet 2008) or structural balance (Saiz et al.

422 2017). Research on food webs has produced several of such theoretical models of network assembly

423 from species traits (e.g. Williams and Martinez 2000): equivalent work for plant association networks

424 is still burgeoning (Lin et al. 2012). 


\section{Moving forward with associations}

427 Using associations as proxies to estimate plant-plant interactions seems to have been deemed a

428 reasonable solution for plants in arid drylands, as evidenced by the breadth of papers relying on this

429 method (e.g. Verdú and Valiente-Banuet 2008, Saiz and Alados 2012, Delalandre and Montesinos-

430 Navarro 2018). This may be motivated by the fact that facilitation (e.g. between nurse plants and their

431 protected species, a type of interaction which is particularly frequent in arid ecosystems) has been

432 shown to be well-captured by association patterns (Freilich et al. 2018). However, our work suggests

433 that plant-plant associations provide valuable information in other ecosystems as well. Strengthening

434 this approach further would require additional evidence to assess whether interactions in a community

435 effectively give rise to the expected association patterns. Such piece of evidence could come from

436 independent trait data (Soliveres et al. 2014). For example, increased functional similarity between two

437 plants could be associated with a higher likelihood of observing a negative association between them

438 (Conti et al. 2017). Another avenue to put the association approach to the test would be to rely on

439 experimental approaches directly measuring interaction strengths (Choler et al. 2001). Given the

440 ballooning number of studies based on plant associations (Losapio et al. 2019), it becomes more and

441 more timely to test such assumptions.

442

443 Another hurdle lying ahead of association-based work is methodological in nature. Much work outside

444 of plant ecology shows that many factors can bias the interaction strengths estimated from spatial

445 associations, such as the scale of sampling (Araújo and Rozenfeld 2014, McNickle et al. 2018,

446 Delalandre and Montesinos-Navarro 2018), the species' habitat preferences (Morueta-Holme et al.

447 2016) or the method used for inference (Barner et al. 2018). Working at the local scale, where the

448 imprint of ecological interactions is generally thought to be stronger, and with sessile species may

449 alleviate some of those shortcomings, but probably not all of them. For example, shared residual 
450 differences in micro-habitat may drive some of the associations between species. Here, our sampling

451 avoided any apparent fine-scale variations in soil characteristics, but residual bias may still be present.

452 For example, in our transects, the presence of pebbles (typical size of 5-20 cm) may make plant

453 individuals only grow in those remaining areas where pebbles are not present. This can produce

454 artefactual positive associations that are not due to any biotic interaction, as plant will cluster in the

455 remaining areas with free bare ground. In our case, this effect is unlikely to affect the trends given the

456 large predominance of negative associations, but it highlights the limits to the precision of association-

457 based approaches.

459 Relying on spatial patterns to make general statements about interactions in plant communities will

460 also require a standardization of methods. One acute point worth highlighting when considering trends

461 in association networks along gradients is controlling for changes in species abundances (Pellissier et

462 al. 2018). If networks are being compared without correction, the trends may not reflect changes in

463 species' behaviors but rather changes in cover. For example, rare species cannot produce negative

464 associations, because even though they may strongly exclude other species in space, their total cover is

465 not sufficient to produce significant spatial segregation (Supplementary Information 4). Reporting

466 ecologically-meaningful variations in community-level metrics (e.g. the total number of negative links,

$467 K^{-}$) must be done with indices that control for species covers (e.g. $K_{S E S}^{-}$). Misinterpreting this property

468 of associations can lead and has led to spurious interpretation of patterns (e.g. Calatayud et al. 2020).

470 To adequately anticipate how ecological communities will respond to global changes, it is necessary to

471 better map empirical interaction networks. This may not always be possible, as pairwise experiments

472 may be prohibitively expensive, or previous knowledge may be missing for the ecosystem of interest

473 (e.g. Kéfi et al. 2015). Association-based approaches provide an alternative yet objective basis to map

474 interactions in situ, preserving the environmental setting in which they occur, and for systems where 
previous knowledge is scarce. They could thus greatly complement traditional approaches, but come

476

477

478

479

480

481

482

483

484

485

486

487

488

489 with their own sets of methodological challenges. Obtaining detailed and accurate empirical interaction networks will thus require leveraging the complementarity of both experimental and observational approaches.

\section{References}

Adler, P. et al. 2001. The effect of grazing on the spatial heterogeneity of vegetation. - Oecologia 128 : 465-479.

Alados, C. L. et al. 2004. Change in plant spatial patterns and diversity along the successional gradient of Mediterranean grazing ecosystems. - Ecol. Model. 180: 523-535.

Araújo, M. B. and Rozenfeld, A. 2014. The geographic scaling of biotic interactions. - Ecography 37: 406-415.

Badan, O. et al. 1995. Les bergeries romaines de la Crau d'Arles. Les origines de la transhumance en Provence. - Gallia 52: 263-310.

Baraza, E. et al. 2006. Conditional outcomes in plant-herbivore interactions: neighbours matter. Oikos 113: 148-156.

Barner, A. K. et al. 2018. Fundamental contradictions among observational and experimental estimates of non-trophic species interactions. - Ecology 99: 557-566.

Blanchet, F. G. et al. 2020. Co-occurrence is not evidence of ecological interactions. - Ecol. Lett. 23: $1050-1063$.

Borer, E. T. et al. 2014. Herbivores and nutrients control grassland plant diversity via light limitation. Nature 508: 517-520.

Bremner, J. M. 1960. Determination of nitrogen in soil by the Kjeldahl method. - J. Agric. Sci. 55: 1133.

Buisson, E. and Dutoit, T. 2006. Creation of the natural reserve of La Crau: Implications for the creation and management of protected areas. - J. Environ. Manage. 80: 318-326.

Buisson, E. et al. 2015. Limiting processes for perennial plant reintroduction to restore dry grasslands: Perennial plant reintroduction in dry grasslands. - Restor. Ecol. 23: 947-954.

Bürkner, P.-C. 2017. brms: An R package for Bayesian multilevel models using Stan. - J. Stat. Softw. 80: $1-28$.

Calatayud, J. et al. 2020. Positive associations among rare species and their persistence in ecological assemblages. - Nat. Ecol. Evol. 4: 40-45. 
Callaway, R. M. 2007. Positive interactions and interdependence in plant communities. - Springer.

Callaway, R. M. et al. 2002. Positive interactions among alpine plants increase with stress. - Nature 417: 844-848.

Carmona, C. P. et al. 2012. Taxonomical and functional diversity turnover in Mediterranean grasslands: interactions between grazing, habitat type and rainfall. - J. Appl. Ecol. 49: 10841093.

Chesson, P. 2000. Mechanisms of maintenance of species diversity. - Annu. Rev. Ecol. Syst. 31: 343366.

Choler, P. et al. 2001. Facilitation and competition on gradients in alpine plant communities. - Ecology

517 82: 3295-3308.

Conti, L. et al. 2017. Environmental gradients and micro-heterogeneity shape fine-scale plant community assembly on coastal dunes. - J. Veg. Sci. 28: 762-773.

D'Amen, M. et al. 2018. Disentangling biotic interactions, environmental filters, and dispersal limitation as drivers of species co-occurrence. - Ecography 41: 1233-1244.

Delalandre, L. and Montesinos-Navarro, A. 2018. Can co-occurrence networks predict plant-plant interactions in a semi-arid gypsum community? - Perspect. Plant Ecol. Evol. Syst. 31: 36-43.

Devaux, J. et al. 1983. Notice de la carte phyto-écologique de la Crau (Bouches du Rhône). - Biol. Écologie Méditerranéenne 10: 5-54.

Díaz, S. et al. 2007. Plant trait responses to grazing: a global synthesis. - Glob. Change Biol. 13: 313341.

Díaz-Sierra, R. et al. 2017. A new family of standardized and symmetric indices for measuring the intensity and importance of plant neighbour effects. - Methods Ecol. Evol. 8: 580-591.

Dureau, R. 1998. Conduite pastorale et répartition de l'avifaune nicheuse des coussouls. Patrimoine naturel et pratiques pastorales en Crau - Rapport du programme LIFE ACE Crau.: 90-97.

Engel, E. C. and Weltzin, J. F. 2008. Can community composition be predicted from pairwise species interactions? - Plant Ecol. 195: 77-85.

Estrada, E. 2010. Quantifying network heterogeneity. - Phys. Rev. E 82: 066102.

Freilich, M. A. et al. 2018. Species co-occurrence networks: Can they reveal trophic and non-trophic interactions in ecological communities? - Ecology 99: 690-699.

Graff, P. and Aguiar, M. R. 2011. Testing the role of biotic stress in the stress gradient hypothesis. Processes and patterns in arid rangelands. - Oikos 120: 1023-1030.

Graff, P. et al. 2007. Shifts in positive and negative plant interactions along a grazing intensity gradient. - Ecology 88: 188-199.

Graff, P. et al. 2013. Changes in sex ratios of a dioecious grass with grazing intensity: the interplay 
between gender traits, neighbour interactions and spatial patterns. - J. Ecol. 101: 1146-1157.

542 Grime, J. P. 1977. Evidence for the existence of three primary strategies in plants and its relevance to

543 ecological and evolutionary theory. - Am. Nat. 111: 1169-1194.

544 Gruntman, M. et al. 2017. Decision-making in plants under competition. - Nat. Commun. 8: 2235.

545 Guimarães, P. R. 2020. The Structure of Ecological Networks Across Levels of Organization. - Annu. 546 Rev. Ecol. Evol. Syst. 51: annurev-ecolsys-012220-120819.

547 Holthuijzen, M. F. and Veblen, K. E. 2016. Grazing effects on precipitation-driven associations

548 between sagebrush and perennial grasses. - West. North Am. Nat. 76: 313-325.

549 550

Kattge, J. et al. 2020. TRY plant trait database - enhanced coverage and open access. - Glob. Change Biol. 26: 119-188.

Kéfi, S. et al. 2007. Spatial vegetation patterns and imminent desertification in Mediterranean arid ecosystems. - Nature 449: 213-217.

Kéfi, S. et al. 2015. Network structure beyond food webs: mapping non-trophic and trophic interactions on Chilean rocky shores. - Ecology 96: 291-303.

Kühn, I. et al. 2004. BiolFlor - a new plant-trait database as a tool for plant invasion ecology: BiolFlor - a plant-trait database. - Divers. Distrib. 10: 363-365.

Le Bagousse-Pinguet, Y. et al. 2012. Release from competition and protection determine the outcome of plant interactions along a grazing gradient. - Oikos 121: 95-101.

Levine, J. M. et al. 2017. Beyond pairwise mechanisms of species coexistence in complex communities. - Nature 546: 56-64.

Lin, Y. et al. 2012. Differences between symmetric and asymmetric facilitation matter: exploring the interplay between modes of positive and negative plant interactions. - J. Ecol. 100: 1482-1491.

Losapio, G. et al. 2019. Perspectives for ecological networks in plant ecology. - Plant Ecol. Divers.: 117.

Maestre, F. T. et al. 2009. Refining the stress-gradient hypothesis for competition and facilitation in plant communities. - J. Ecol. 97: 199-205.

McNickle, G. G. et al. 2018. Checkerboard score-area relationships reveal spatial scales of plant community structure. - Oikos 127: 415-426.

Michalet, R. et al. 2006. Do biotic interactions shape both sides of the humped-back model of species richness in plant communities? - Ecol. Lett. 9: 767-773.

Molinier, R. and Tallon, G. 1950. La végétation de la Crau. - Rev. Générale Bot.: 525-540.

Morueta-Holme, N. et al. 2016. A network approach for inferring species associations from cooccurrence data. - Ecography 39: 1139-1150. 
Novoplansky, A. 2009. Picking battles wisely: plant behaviour under competition. - Plant Cell Environ. 32: 726-741.

Odriozola, I. et al. 2017. Grazing exclusion unleashes competitive plant responses in Iberian Atlantic mountain grasslands. - Appl. Veg. Sci. 20: 50-61.

Pellissier, L. et al. 2018. Comparing species interaction networks along environmental gradients: Networks along environmental gradients. - Biol. Rev. 93: 785-800.

R Core Team 2020. R: A Language and Environment for Statistical Computing. - R Foundation for Statistical Computing.

Rajala, T. et al. 2019. When do we have the power to detect biological interactions in spatial point patterns? - J. Ecol. 107: 711-721.

Römermann, C. et al. 2005. Influence of former cultivation on the unique Mediterranean steppe of France and consequences for conservation management. - Biol. Conserv. 121: 21-33.

Saatkamp, A. et al. 2020. Romans Shape Today's Vegetation and Soils: Two Millennia of Land-Use Legacy Dynamics in Mediterranean Grasslands. - Ecosystems in press.

Saiz, H. and Alados, C. L. 2011. Structure and spatial self-organization of semi-arid communities through plant-plant co-occurrence networks. - Ecol. Complex. 8: 184-191.

Saiz, H. and Alados, C. L. 2012. Changes in semi-arid plant species associations along a livestock grazing gradient. - PloS One 7: e40551.

Saiz, H. et al. 2017. Evidence of structural balance in spatial ecological networks. - Ecography 40: 733-741.

Saiz, H. et al. 2018. The structure of plant spatial association networks is linked to plant diversity in global drylands. - J. Ecol. 106: 1443-1453.

Sanderson, J. G. and Pimm, S. L. 2015. Patterns in nature: the analysis of species co-occurrences. - The University of Chicago Press.

Selbie, D. R. et al. 2015. The Challenge of the Urine Patch for Managing Nitrogen in Grazed Pasture Systems. - In: Advances in Agronomy. Elsevier, pp. 229-292.

Smit, C. et al. 2009. Inclusion of biotic stress (consumer pressure) alters predictions from the stress gradient hypothesis. - J. Ecol. 97: 1215-1219.

Soliveres, S. and Maestre, F. T. 2014. Plant-plant interactions, environmental gradients and plant diversity: A global synthesis of community-level studies. - Perspect. Plant Ecol. Evol. Syst. 16: 154-163.

Soliveres, S. et al. 2014. Functional traits determine plant co-occurrence more than environment or evolutionary relatedness in global drylands. - Perspect. Plant Ecol. Evol. Syst. 16: 164-173.

Soliveres, S. et al. 2015. Moving forward on facilitation research: response to changing environments and effects on the diversity, functioning and evolution of plant communities: Facilitation, 
610 Steinauer, E. M. and Collins, S. L. 1995. Effects of Urine Deposition on Small-Scale Patch Structure in 611 Prairie Vegetation. - Ecology 76: 1195-1205.

612 Thebault, E. and Fontaine, C. 2010. Stability of Ecological Communities and the Architecture of 613 Mutualistic and Trophic Networks. - Science 329: 853-856.

614 Tielbörger, K. and Kadmon, R. 2000. Temporal environmental variation tips the balance between 615 facilitation and interference in desert plants. - Ecology 81: 1544-1553.

616 Tilman, D. 1982. Resource competition and community structure. - Princeton university press.

617 Tylianakis, J. M. and Morris, R. J. 2017. Ecological networks across environmental gradients. - Annu. 618 Rev. Ecol. Evol. Syst. 48: 25-48.

619 Valiente-Banuet, A. and Verdú, M. 2008. Temporal shifts from facilitation to competition occur 620 between closely related taxa. - J. Ecol. 96: 489-494.

621 Vehtari, A. et al. 2017. Practical Bayesian model evaluation using leave-one-out cross-validation and 622 WAIC. - Stat. Comput. 27: 1413-1432.

623 Verdú, M. and Valiente-Banuet, A. 2008. The Nested Assembly of Plant Facilitation Networks 624 Prevents Species Extinctions. - Am. Nat. 172: 751-760.

625 Vries, D. M. 1954. Constellation of frequent herbage plants, based on their correlation in occurrence: 626 with 1 table and 2 figures. - Vegetatio 5-6: 105-111.

627 Williams, R. J. and Martinez, N. D. 2000. Simple rules yield complex food webs. - Nature 404: 180628183.

629 Wootton, J. T. 1994. The nature and consequences of indirect effects in ecological communities. $630 \quad$ Annu. Rev. Ecol. Syst. 25: 443-466. 


\section{Figures}

633

634

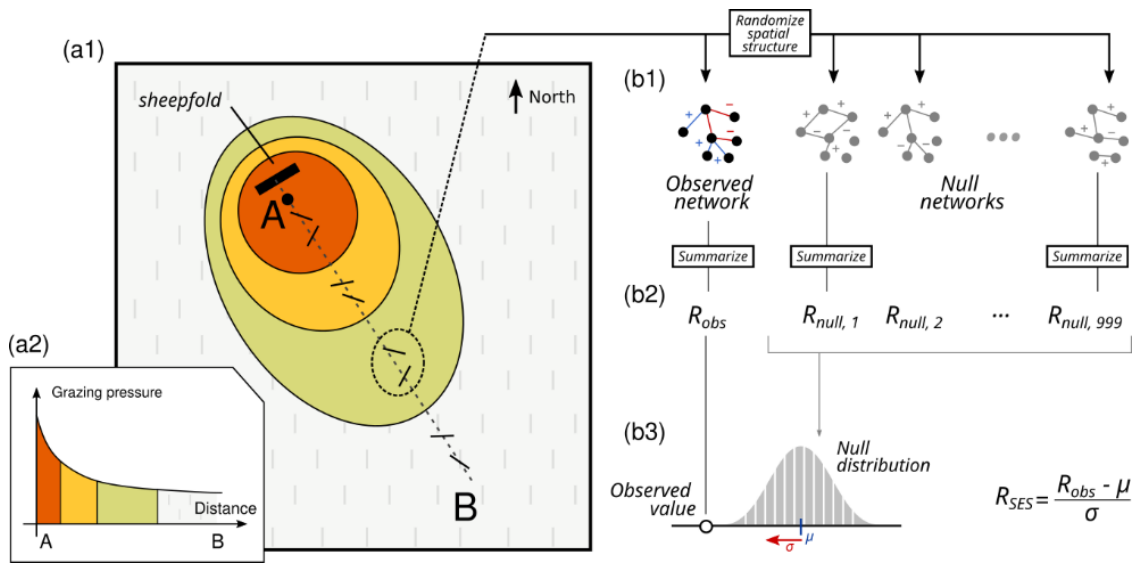

635 Figure 1. General variation of vegetation around a sheepfold and procedure used to calculate

636 community-level network properties. Vegetation can be divided into different "belts" (a1), whose

637 spatial extents depend on the grazing pressure (a2) and which are most extended towards the south-east

638 because of the sheepfold buffering the herds against dominant winds (a1). We carried out two transects

639 per vegetation type (i.e. per belt) in the south-east direction, leading to one observed association

640 network and 999 'null' networks per pair of transect (b1). Both observed and null networks were

641 summarized into summary metrics, for example $R$, the relative frequency of positive to negative

642 associations (b2). The deviation of the observed summary metric from the null expectation was then

643 computed using standardized effect size, yielding cover-corrected community-level metrics such as

$644 R_{S E S}(\mathrm{~b} 3)$.

645

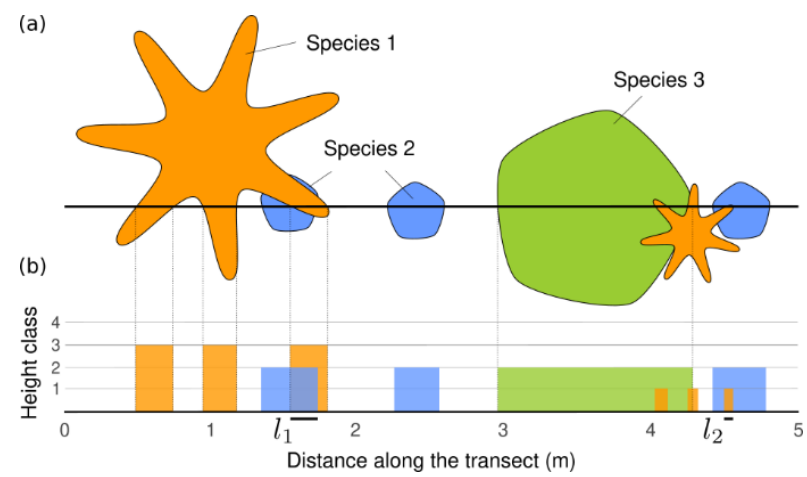


647 Figure 2. Design of the transect surveys. Panel (a) represents a top-down view of plant individuals

648 spread along a line transect (black line). We recorded all intersections of the line with plant parts, along 649 with a class of height (b). The total overlap between species was then computed along the transect. For 650 example, here $O_{12}$, the total overlap between species 1 and 2 is given by $O_{12}=l_{1}+l_{2}$. We used pairs 651 of transects in the field but in this figure, only one transect is represented for simplicity. 
(a)

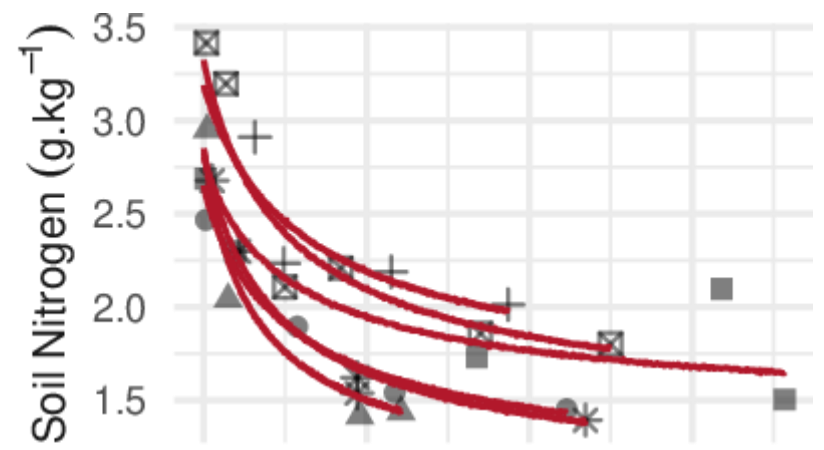

(b)

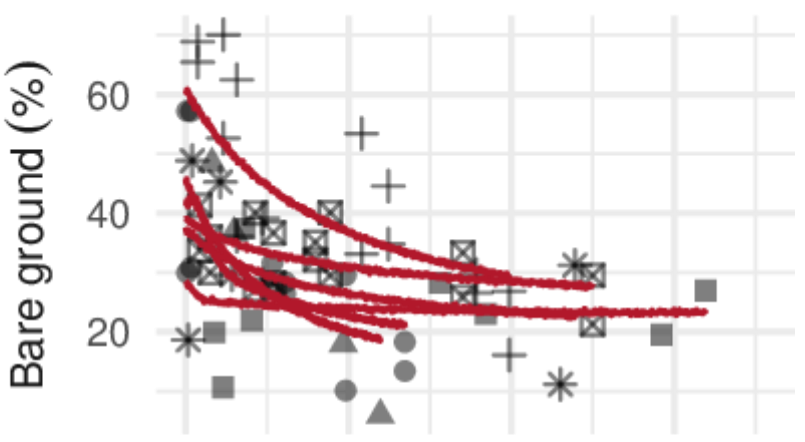

(c)

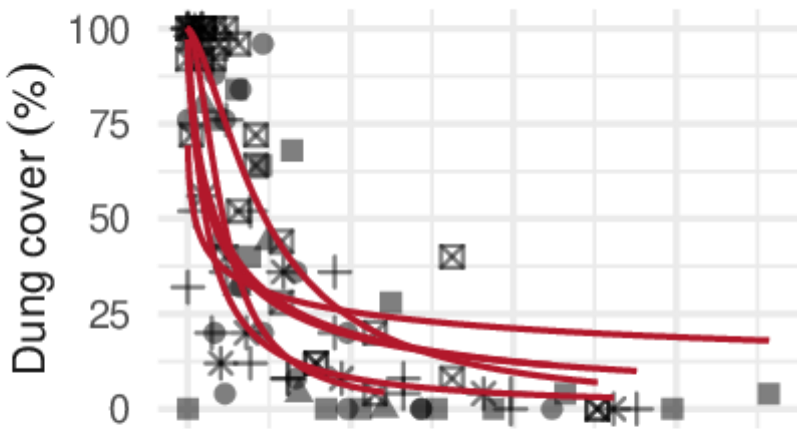

(d)

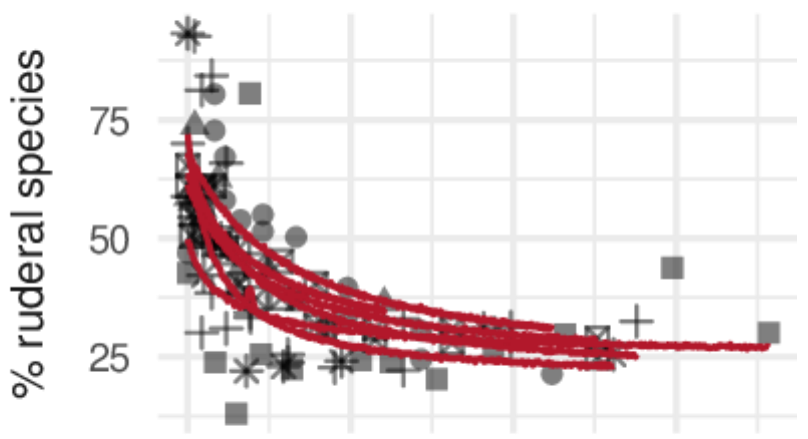

(e)

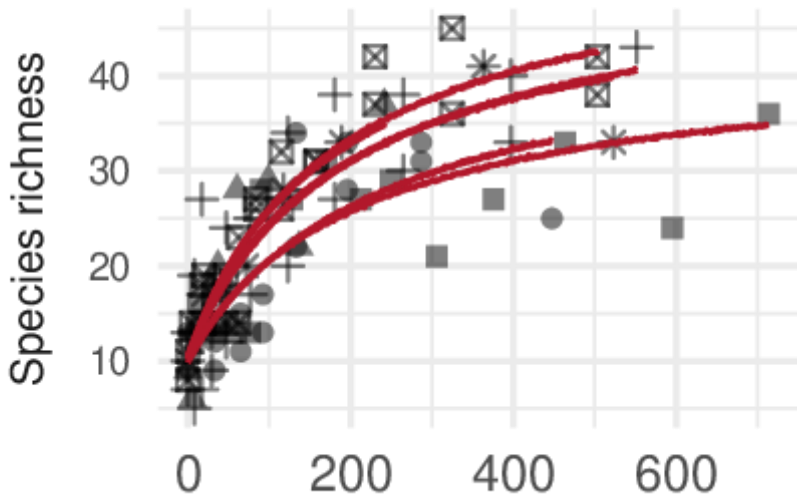

Distance to sheepfold (m) 
653 Figure 3. Variations in soil nitrogen, bare ground, dung cover, percentage of ruderal species, species

654 richness as a function of distance to the sheepfold. The shape of the points and the separate trend lines

655 indicate the different sites. Red trend lines are fits of a saturating function (the relationship described in

656 equation 2), with different link functions depending on the nature of the response variable

657 (proportional, continuous or discrete). The percentage of ruderal species is the proportion of the total

658 plant cover made up of ruderal species sensu Grime’s CSR classification (Grime 1977). 


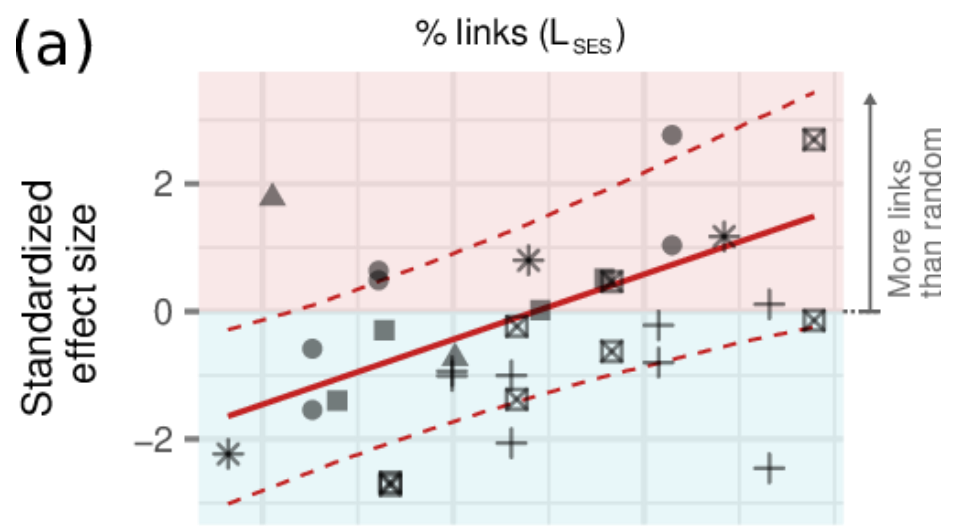

(b) \% neg. links $\left(\mathrm{K}_{\mathrm{SES}}^{-}\right)$

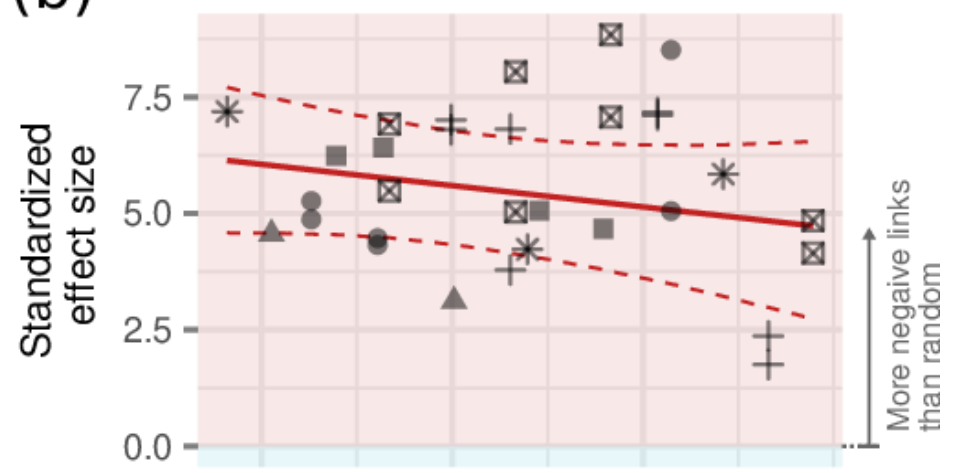

(c)

$\%$ pos. links $\left(\mathrm{K}_{\mathrm{SES}}^{+}\right)$

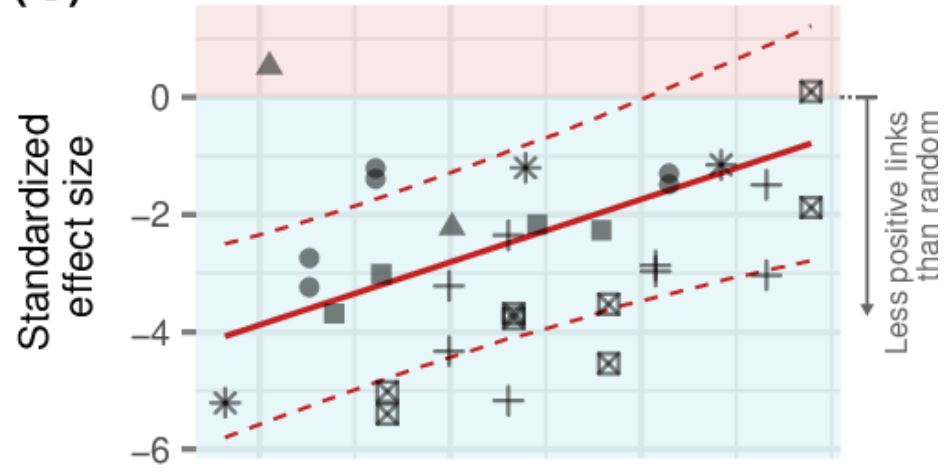

(d)

Association ratio $\left(\mathrm{R}_{\mathrm{SES}}\right)$

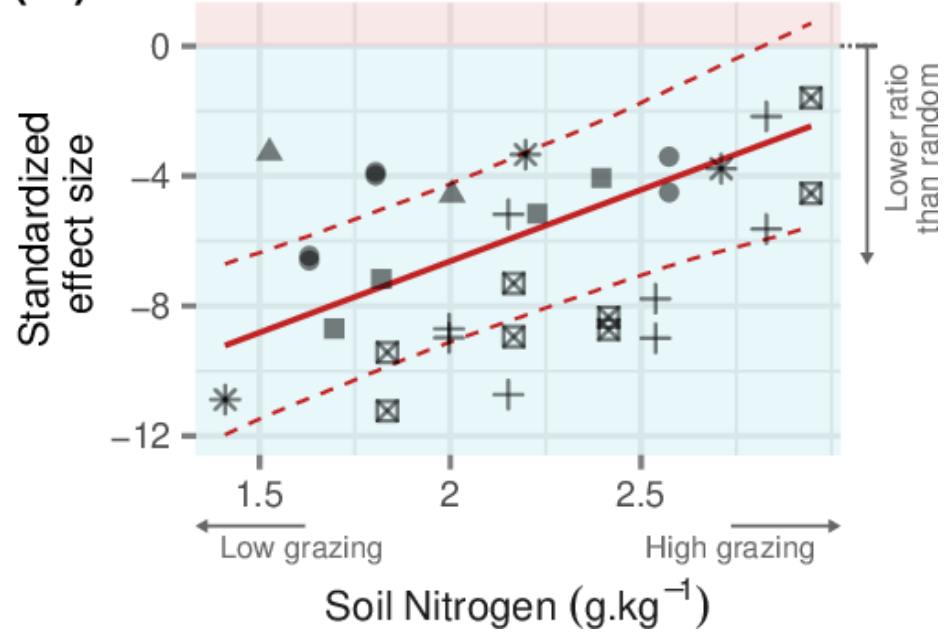


661 Figure 4. Total fraction of links $\left(L_{S E S}\right)$, fraction of negative $\left(K_{S E S}^{-}\right)$, positive links $\left(K_{S E S}^{+}\right)$and association 662 ratio $\left(R_{S E S}\right)$ as a function of grazing pressure. Trend lines indicate linear regressions along the grazing 663 gradient, as measured through total Nitrogen, with dashed lines representing the 95\% credible interval 664 on the predicted mean. Red and blue backgrounds highlight the areas corresponding to positive and 665 negative values, respectively. Point shapes indicate different sites.

666
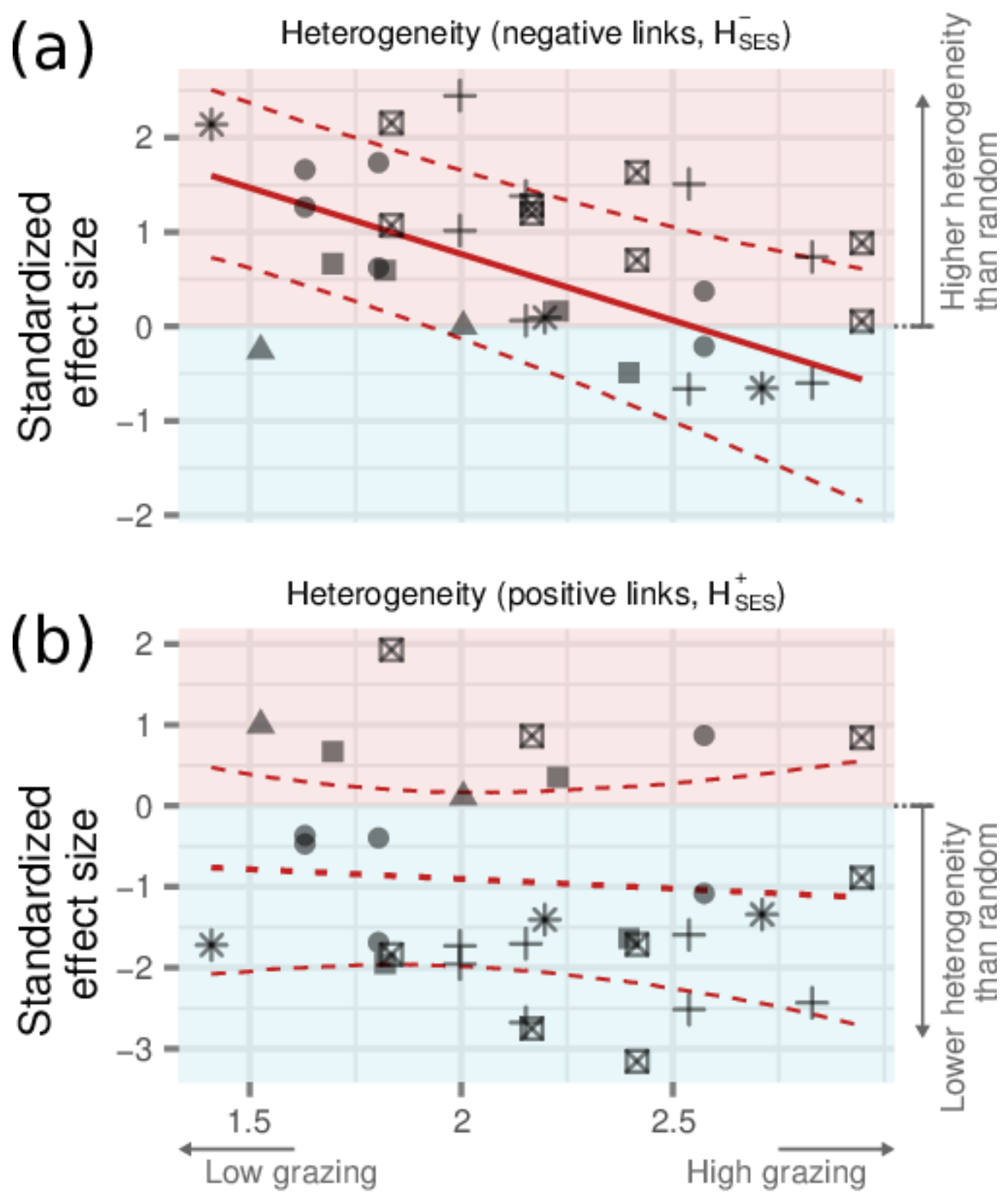

668 Figure 5. Trends of the heterogeneity of negative $\left(H_{S E S}^{-}, \mathrm{a}\right)$ and positive $\left(H_{S E S}^{+}, \mathrm{b}\right)$ links. Red and blue 
669 backgrounds highlight the areas corresponding to positive and negative values, respectively. Trend

670 lines indicate linear regressions along the grazing gradient, as measured through total Nitrogen, with

671 dashed lines representing the $95 \%$ credible interval on the predicted mean. The posterior distribution

672 for the $H_{S E S}^{+}$slope included zero between its $2.5 \%$ and $97.5 \%$ quantiles, suggesting no effect of grazing,

673 so the trend is represented with a dotted line.

674 


\section{Supplementary information S1}

\section{Description of the site and sampling protocol}

In La Crau, herds of sheep are not within enclosures but lead by shepherds within open, extensive but delimited areas (most of them above 70 ha, with a maximum of 540 ha; Tatin et al., 2013). Most of these areas include a sheepfold built next to a shelter for the shepherd. Sheep are gathered in the sheepfold at night or, because of the large size of the herds (on average 1,600 individuals; Tatin et al., 2013), in temporary enclosures next to it. As a result, sheep spend more time near the sheepfold than elsewhere in the grazing area, resulting in a natural gradient of grazing pressure and other impacts related to the presence of sheep (e. g. nutrient enrichment through dung/urine deposition and trampling). This gradient is most extended towards the south-east, which is the main direction of strong dominant winds.

Vegetation communities respond to this grazing gradient, resulting in a strong species turnover with ruderal, nitrophilous communities near the sheepfold (Figure S1, and typical "Coussoul"-type communities (dominated by Brachypodium retusum and Asphodelus ayardii) where grazing is at its lowest, away from the sheepfold (Molinier \& Tallon, 1950; Gomila, 1987). Previous work often classifies vegetation communities in four types, two being the ones described above, along with two others corresponding to intermediate levels of grazing, one defined by the presence of Onopordum illyricum, and another by the dominance of Trifolium subterraneum (Molinier et Talon, 1950). In the absence of accurate measurement of the grazing pressure, we reused these four known vegetation types to guide our surveys and ensure that we documented a large range of grazing levels.

We first carried a quadrat-based survey and recorded the presence/absence of all species in a grid of 5 by $520 \times 20 \mathrm{~cm}$ subquadrats (resulting in a quadrat size of $1 \mathrm{~m}^{2}$ ). The first quadrat was placed as close as possible to the sheepfold entrance. The spacing between quadrats then followed a geometric series, i.e. the second quadrat was placed at $d_{2}=2 \mathrm{~m}$ from the first, then subsequent quadrats were placed such that $d_{n+1}=b * d_{n}$. $b$ was between 1.2 and 1.5 depending on each site. Adjustments to this spacing rule were made to avoid local disturbances unrelated to grazing (e.g. dirt roads). We recorded in a $3 \times 6 \mathrm{~m}$ area around each quadrat the presence of indicator species, which were those used in the literature to define the four aforementioned vegetation types (Molinier \& Tallon, 1950; Gomila, 1987). Basing the sampling on these indicator species allowed us to make sure we documented all vegetation types, hence a large range of grazing pressures, even in the absence of its direct measurement. At a given site, we stopped surveying once two quadrats were done in the "Coussouls"-type community (the criterion used was Brachypodium retusum at more than $50 \%$ cover in a quadrat).

Based on indicator species, we assigned in the field each quadrat to one of the four types of community. We thus obtained ranges of quadrats for each site and type of plant community. For example, for a site, we could have quadrat 1 to 3 in the most nitrophilous community, then 3-5 in the first intermediate community, 5-8 in the second intermediate community, then 8-10 in the "Coussouls"-type community. We then carried out a pair of transect in each community type, and 
because this sampling was repeated twice for some sites, it resulted in at most 8 pairs of transects per site (i.e. 16 transects in total).

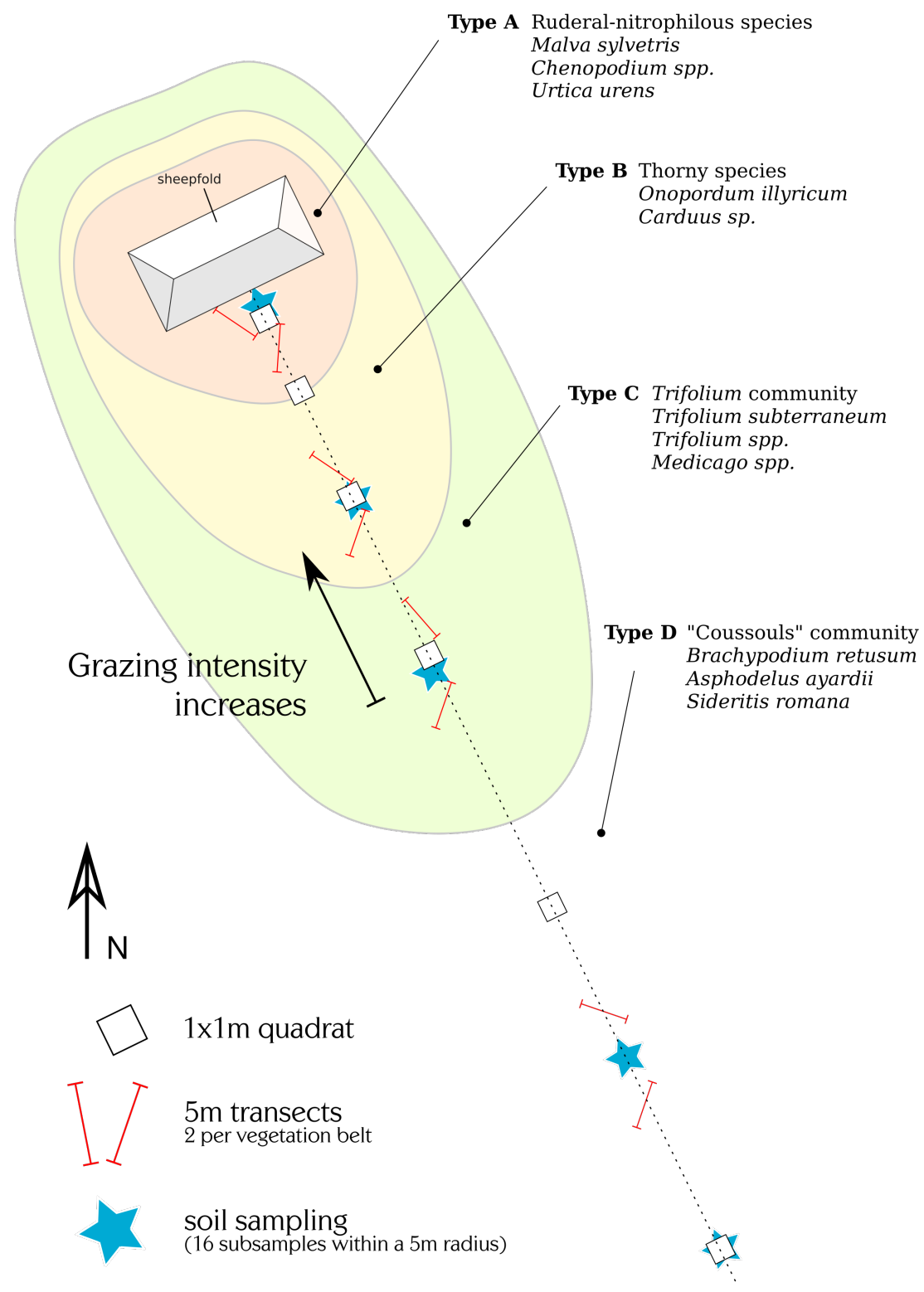

Figure S1 - Graphical summary of the different types of surveys carried out for a given site. Four plant community types have been identified based on a set of indicator species, as indicated by colors and labels. Labels indicate notable species present in each belt. Quadrats were carried out at different distances from the sheepfold entrance. In each belt, a pair of $5 \mathrm{~m}$ transects was laid out to measure the spatial distribution of species individuals. Soil was also sampled at least four times per site at the average distance of each pair of transects.

In addition to quadrats and transects, soil samples were taken between Oct. 16 and Oct. 312017 (when sheep are absent). One sample was taken at the average distance of each transect pair, sometimes complemented by samples placed at quadrat positions so that soil characteristics could be interpolated at each quadrat and transect position. This resulted in 4 to 6 soil samples per site. 
Each soil sample was taken by mixing 16 regularly-spaced sub-samples in a circle of $4 \mathrm{~m}$ around a center point. All surface litter was scraped and approximately $125 \mathrm{cL}$ of soil was sampled at each point between 0 and $10 \mathrm{~cm}$. All subsamples were mixed in a bowl and a compound sample of $400 \mathrm{~g}$ was taken. This latter sample was dried for at least $72 \mathrm{~h}$ at $40^{\circ} \mathrm{C}$, sieved to $2 \mathrm{~mm}$ and sent for analyses (Laboratoire Teyssier, 5 route des Junchas, 26460 Bourdeaux, France). Soil analyses included pH (in water), Metson total CEC (Cation Exchange Capacity), total $\mathrm{CaCO}_{3}$, total organic matter, total Nitrogen, total Phosphorus (Olsen method), exchangeable K, Mg, Ca and Na.

\section{Estimating Grazing pressure}

A stated earlier, grazing in La Crau is centered around sheepfolds. During the day the shepherd will lead the sheep out and come back at night close to the sheepfold (Figure 2). As a result, disturbance due to the presence of sheep is strong next to the sheepfold, and decreases as one moves away from it. However, there are very few direct measurements of the shape of this relationship.

a)

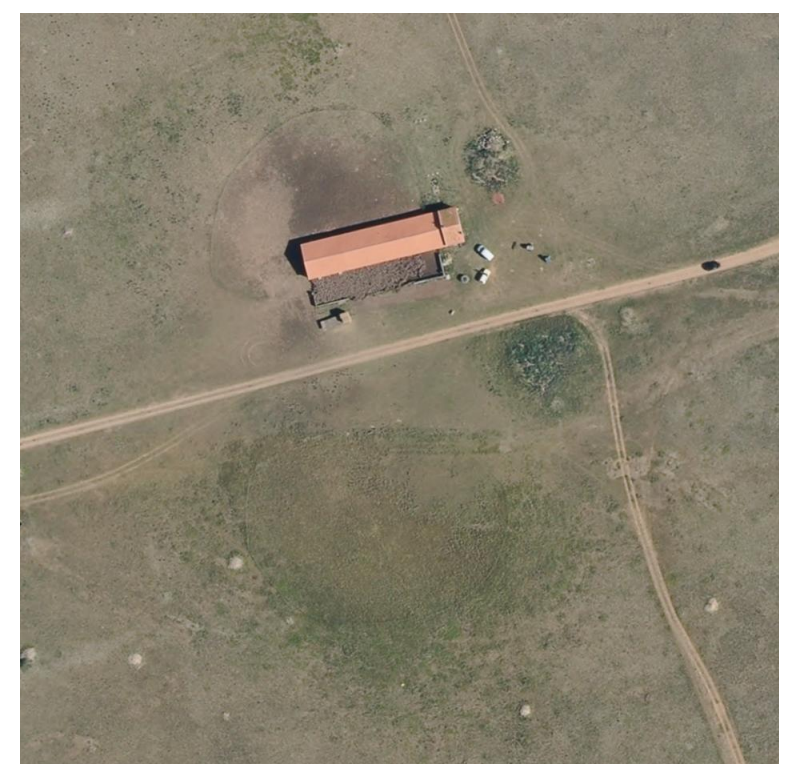

b)

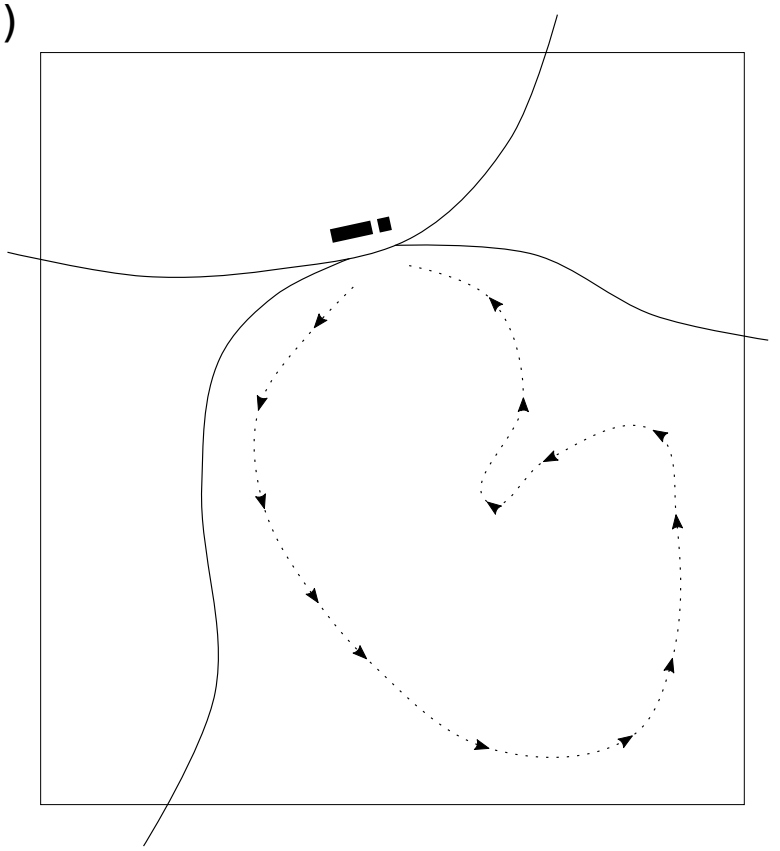

Figure S2 - (a) Aerial view of a sheepfold (Google maps), in which the nitrophilous plant communities (dark green) are clearly visible. (b) The sheep stays close to the sheepfold at night, then the herd is conducted during the day by the shepherd: as a result, sheep spend more time close to the sheepfold than far from it.

To our knowledge, only one study (Dureau, 1998) attempted to measure such relationship directly. Extracting the reported values and plotting grazing pressure against distance, we obtain the following relationship: 


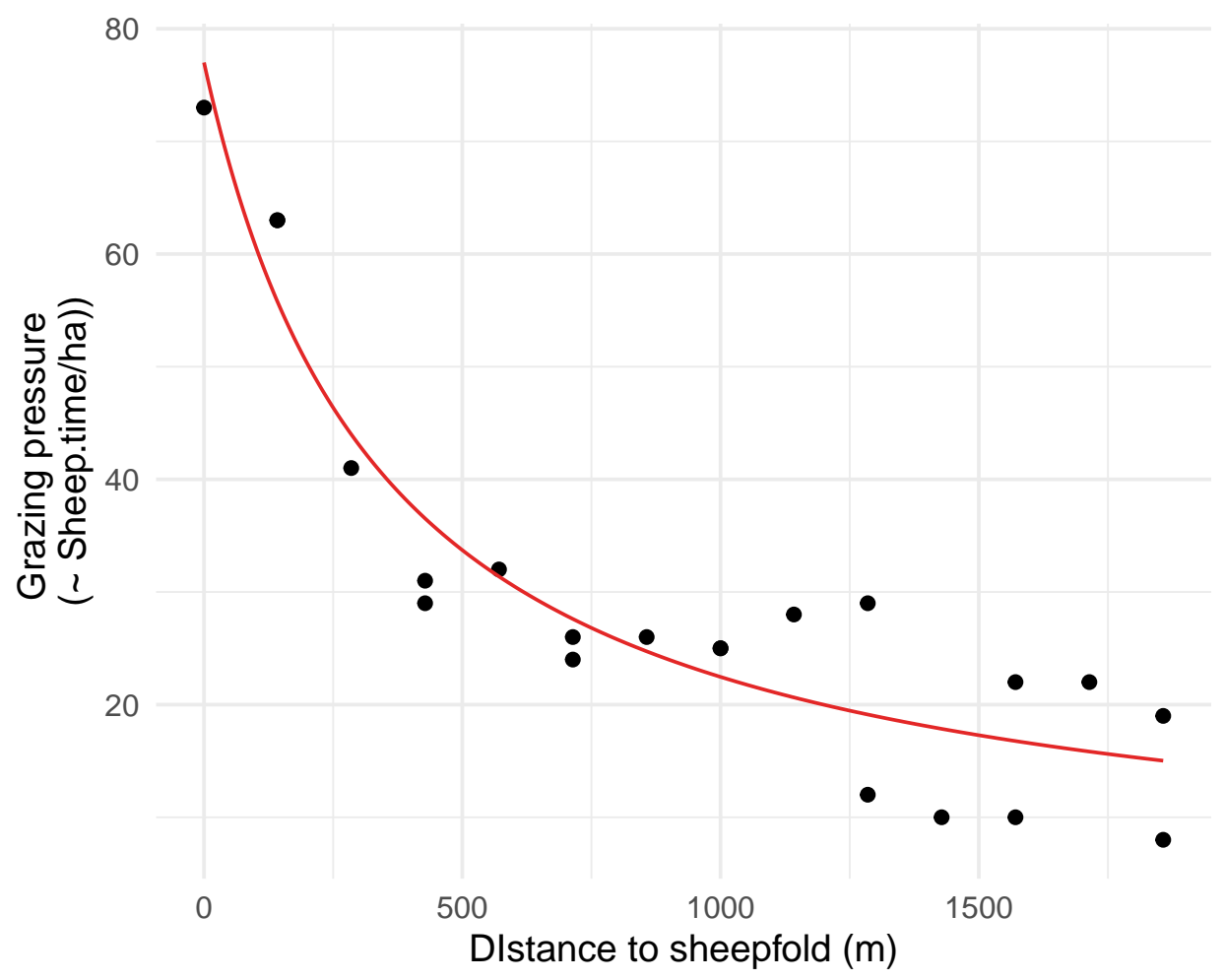

Figure S3 - Relationship found between distance to the sheepfold and grazing pressure by Dureau et al. (1998).

The above plot suggests that grazing pressure is well-described by the following relationship (drawn as a red line above), where $\mathrm{x}$ is the distance to the sheepfold:

$$
G(x)=G_{i n f}+\frac{G_{0}-G_{i n f}}{1+\lambda x}
$$

where $\lambda$ characterizes how fast the grazing pressure decays as a function of distance to the sheepfold entrance. Writing $\tau=1 / \lambda$ and $\Delta G=G_{\text {inf }}-G_{0}$, this equation can be rewritten as:

$$
G(x)=\frac{\tau G_{0}+\left(G_{0}+\Delta G\right) x}{\tau+x}
$$

In this equation,

- $\tau$ characterizes the extent of the spatial gradient

- $G_{0}$ characterizes the grazing pressure near the sheepfold entrance

- $\Delta G$ characterizes the difference in grazing pressure between the areas near the entrance and areas far from the sheepfold ("at infinite distance").

We found that many soil-related variables showed trends that could be described by such relationship, suggesting that soil parameters could be used as a proxy for the position of a given transect along the grazing gradient (Figure S4). 


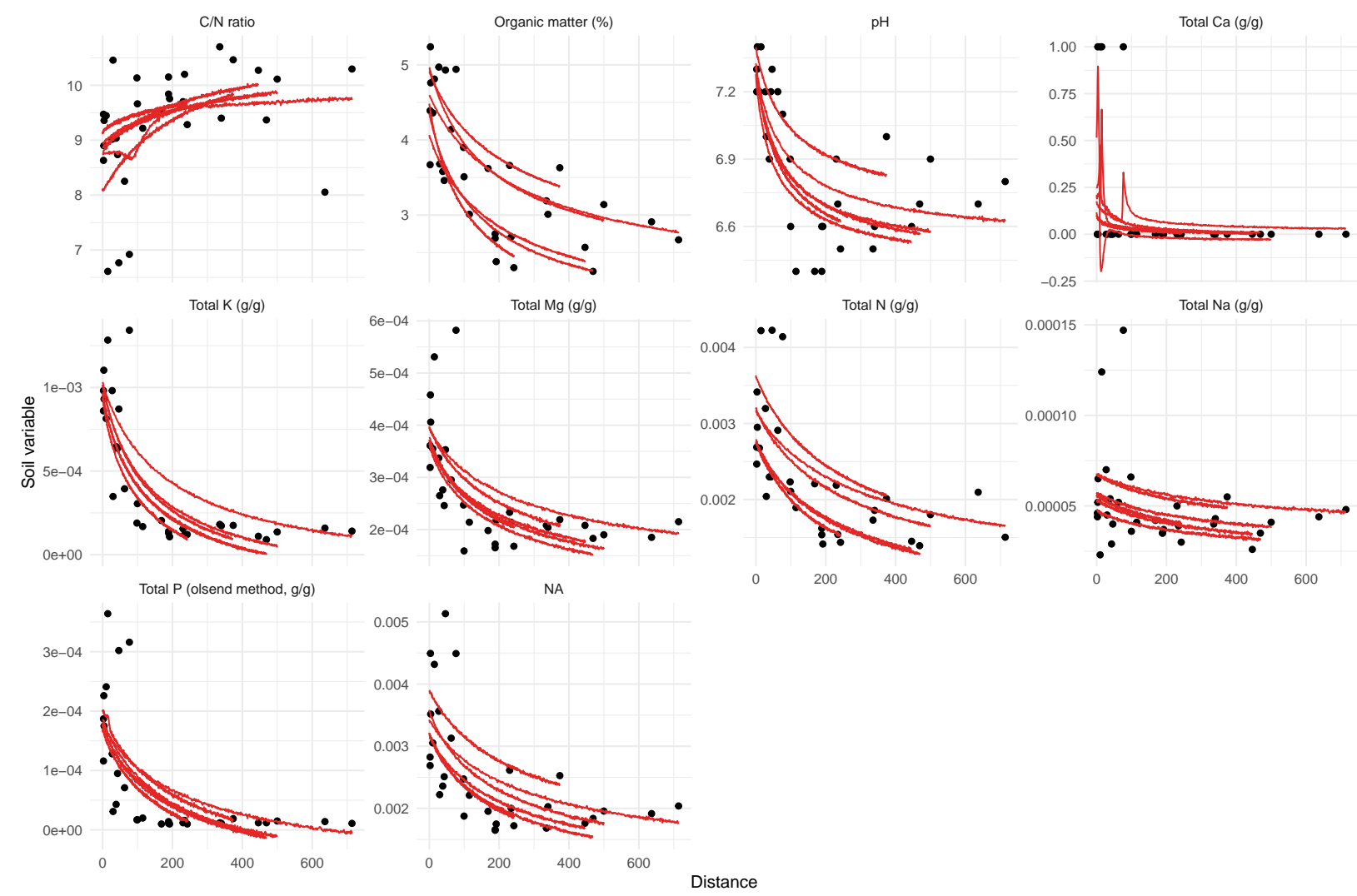

Figure S4 - Soil variables measured at different distances to the sheepfold, and inverse-distance fits (similar to the form presented in Equation 2). Points indicate soil samples and trend lines indicate trends for different sites. Note that to simplify computations, the fits assume a normal error around the mean, even though this may not be realistic for all variables. The fits presented here include all displayed points, including outliers.

We focused on the variations of total nitrogen to estimate grazing pressure because it was expected to be the most directly correlated to herbivore defecation around and in enclosures (Selbie, et al. 2015, Steinauer and Collins 1995), and was well-measured by the soil analyses (compared to phosphorus for instance for which small concentrations had similar measured values). Other soil variables were more indirectly linked to sheep presence (e.g. pH), or results reported by the soil analyses were unreliable (e.g. total Ca, were values are only 0 or 1 ). It is worth noting however that most soil variables showed correlated trends along the grazing gradient.

Assuming that the total $\mathrm{N}$ in the soil is linearly related to sheep activity (i.e. that $N \approx a * G+b$ with $a$ and $b$ being constants), we can model its relationship with distance to obtain an estimate of grazing index. In the main text analyses, we removed three outliers from the regression that did not fit model assumptions (points with $\mathrm{N}>0.0035$ in figure S4). These outliers exhibited a much higher content in $N_{t o t}$ that was predicted by an inverse-distance relationship, and were probably the result of sample contamination (probably a sampling error involving remaining dung in the soil sample).

For the analyses described in the main text, we fitted a model of the following form:

$$
N(x)=\frac{\tau N_{0}+\left(N_{0}+\Delta N\right) x}{\tau+x}
$$


where :

- $N_{0}$ is the estimated soil Nitrogen content at the sheepfold entrance

- $\Delta N$ is the estimated difference in soil Nitrogen content between areas far from the sheepfold (where grazing pressure is at its minimum) and areas close to it

- $\tau$ is the spatial extent of the gradient (proportional to the distance at which grazing pressure has decayed by half of its maximum value). It represents a distance (in meters).

We fitted this model using a bayesian setting and the following conservative priors (to prevent overfitting) on population-level effects:

$$
\begin{gathered}
N_{0} \sim \mathcal{N}\left(\mu_{N}, 3 * \sigma_{N}\right) \\
\Delta N \sim \mathcal{N}\left(0,3 * \sigma_{N}\right) \\
\tau \sim \mathcal{N}(200,200)
\end{gathered}
$$

where $\sigma_{N}$ is the standard deviation of the observed values of total nitrogen, pooled for all sites. We used a site-level random effect on the estimates of $N_{0}, \Delta N$ ) and $\lambda$, and used the following Student distributions with three degrees of freedom and the following parameters:

$$
\begin{gathered}
N_{0} \sim \text { Student }_{3}\left(\text { mean }=0, s d=5 * \sigma_{N}\right) \\
N \sim \text { Student }_{3}\left(\text { mean }=0, s d=5 * \sigma_{N}\right) \\
\tau \sim \text { Student }_{3}(\text { mean }=0, s d=200)
\end{gathered}
$$

We modelled a correlated group-level effect between $N_{0}$ and $\Delta N$ because it was found to produce better fits (checked visually).

The model was fit using the $\mathrm{R}$ package brms (see the included file functions.R, line 109 for the implementation).

For all pairs of transect, we took the average predicted total $\mathrm{N}$ value as an index of grazing pressure.

\section{Sensitivity to association cutoff $\alpha$}

We retained a positive association between two species when their total overlap was above the $87.5 \%$ quantile of the null distribution, i.e. using $\alpha=0.25$ cutoff $(100 \%-\alpha / 2=0.875$ or $87.5 \%)$. Similarly, we retained negative associations when the total overlap was below the $12.5 \%$ quantile $(\alpha / 2)$. $\alpha$ here represents a tradeoff. Larger values of $\alpha$ yield networks with a higher proportion of links, which may be interesting to compute aggregate statistics such as the proportion of links $(L)$. However, these associations can be weak (i.e. they only weakly aggregate or segregate in space). Smaller values of $\alpha$ will yield networks with links between plants that are only strongly positively or negatively associated, but these networks can be very sparse (low number of links) and thus some community-level metrics (e.g. the total number of links) can be badly estimated.

In figure S5, we investigate the influence of the value of $\alpha$ on the trends we observe along the gradient. We report the estimates on the slopes of the linear trends displayed in Figure 4 and 5 in main text, but with varying values of $\alpha$. 


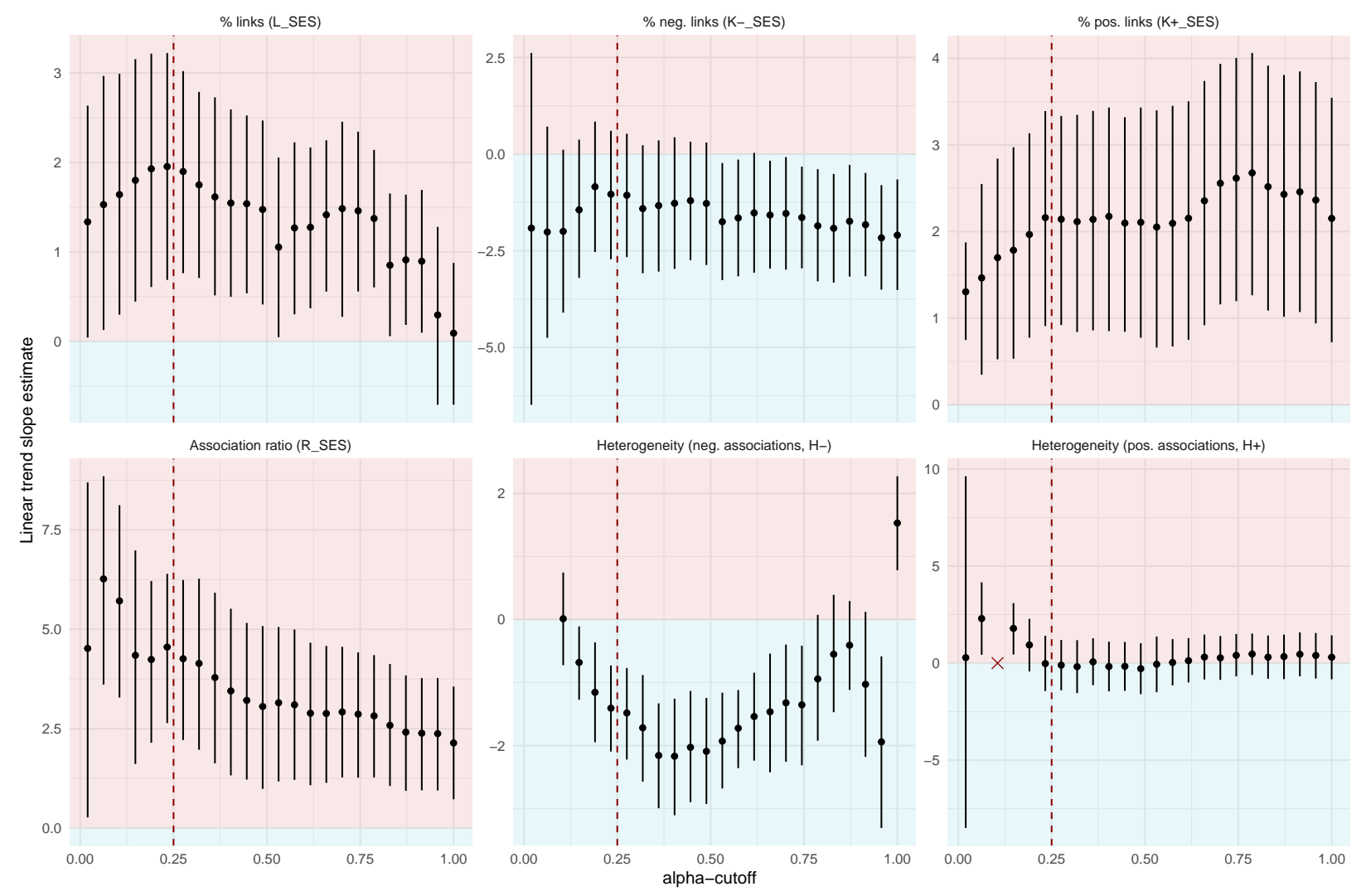

Figure S5 - Results of sensitivity analyses. Black bars indicate the $2.5 \%$ and $97.5 \%$ quantiles of the credible interval on the slope, and the black points the mean estimate. Red crosses indicate values of $\alpha$ for which a quadratic model was selected over a linear model to describe the trends of the network metric along the gradient. The dashed vertical line indicates the value chosen for the trends reported in main text (0.25).

For most metrics, it appears that the trends stay stable for a wide variety of $\alpha$ cutoffs, suggesting that our conclusions are robust and not the result of a specific choice of value for $\alpha$. While some values of $\alpha$ yield quadratic models, this behavior is sporadic and does not reflect the general pattern.

\section{Species'abundances and bias in associations}

The ability of a species to exhibit negative or positive associations varies with its abundance. Specifically, species under a given total cover cannot exhibit positive associations. We run here a small simulation with synthetic data to highlight this bias in association networks.

We first consider a transect with two large individuals totalling 50\% cover each. Figure S6 represents a transect with such individuals, which is of the same nature as the data recorded in this study. 


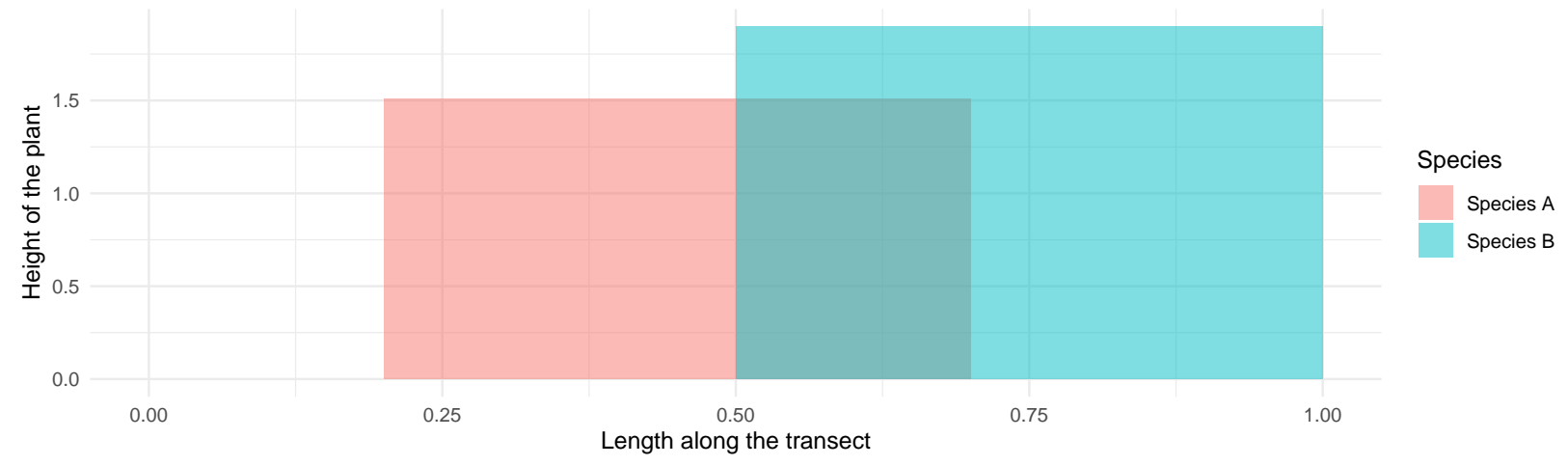

Figure S6 - A transect with two large individuals. The x-axis is the length along the transect, and the y-axis is the height of the plant individuals (see also Figure $2 \mathrm{~b}$ in main text).

In such situation, the total observed overlap is $0.2(20 \%)$. The null distribution of overlap (given randomized positions of the individuals along the transect) for the species pair is in Figure S7.

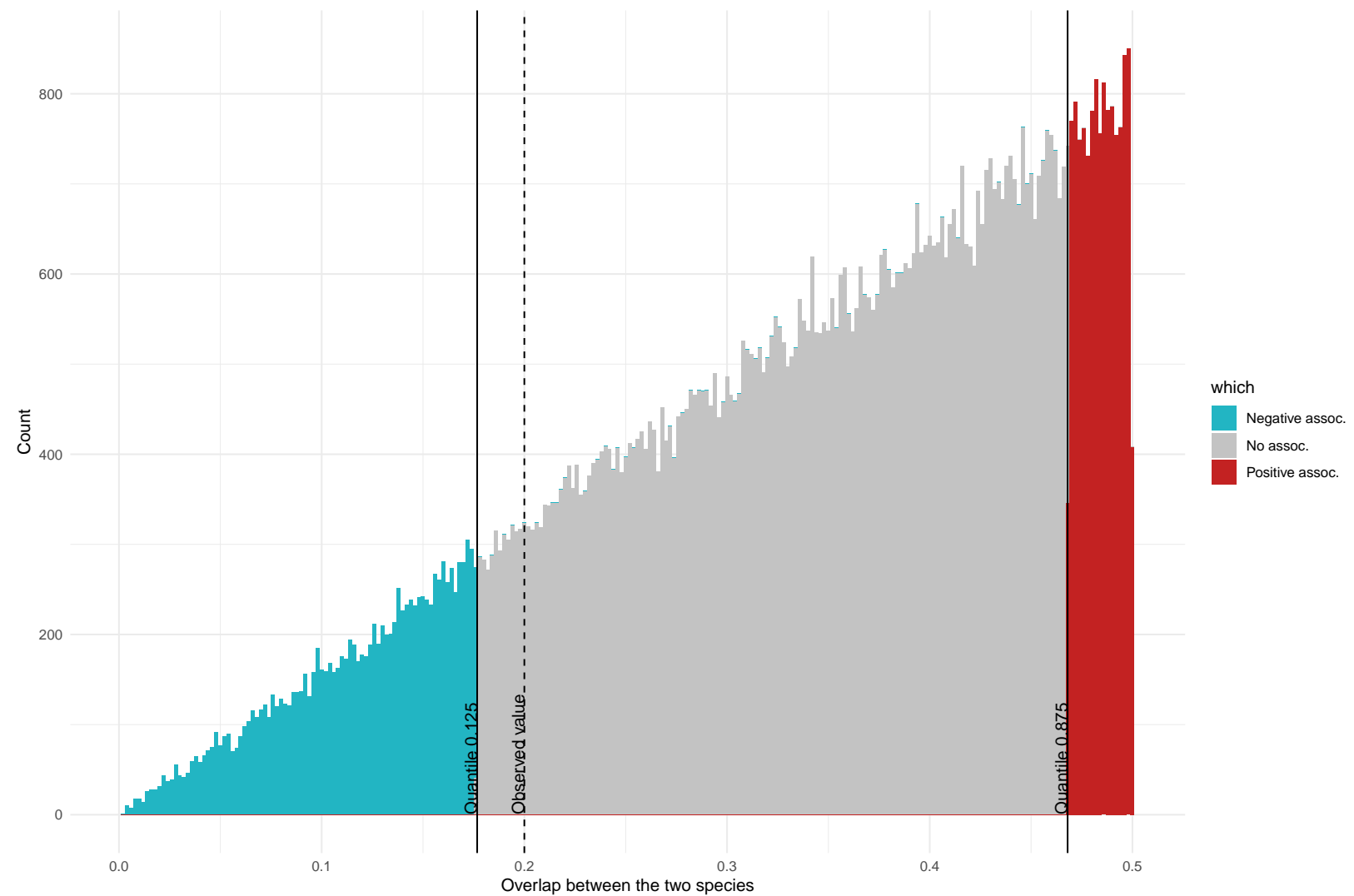

Figure S7 - Null distribution of overlap for a transect with a pair of species with high cover (50\%). The continuous lines indicate the quantiles above or under which a significant positive or negative association is retained, respectively (for $\alpha=0.25$ ). The dashed line indicates the observed value.

We see that the null distribution has values above and below the cutoff used to retain a positive or negative associations (the red and blue areas, respectively). Thus, the two species can exhibit both a positive or a negative association, depending on their observed overlap.

Note that this distribution has no values above 0.5 (50\%), which is the maximum possible overlap 
between the two species.

We now consider the case of two rare species with low cover (10\%) :

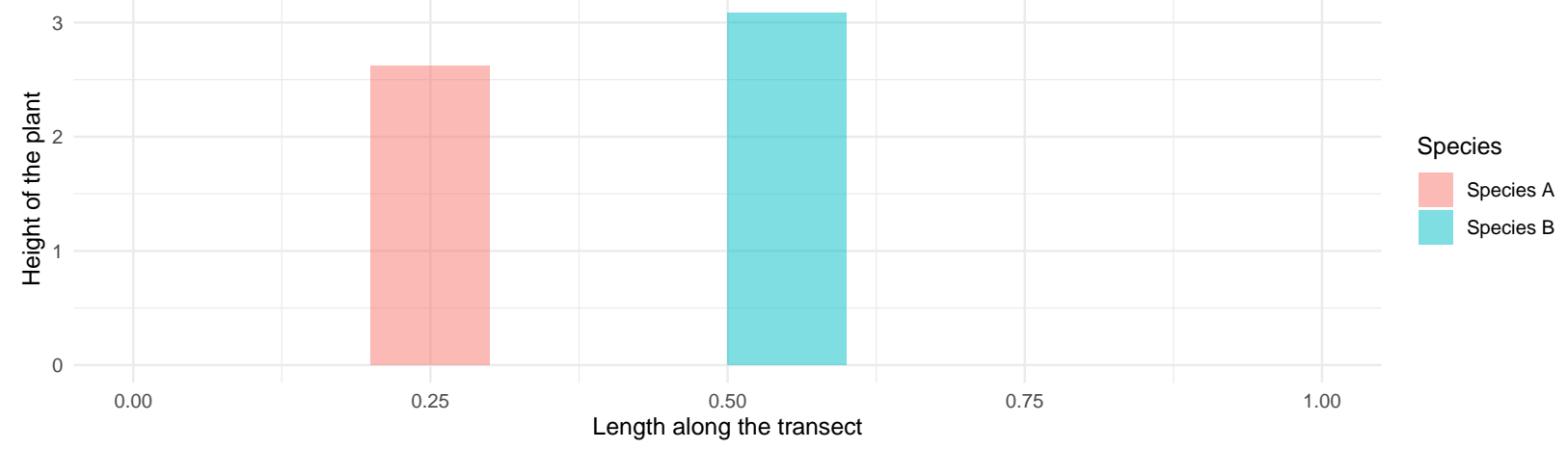

Figure S8 - A transect with two small individuals. The x-axis is the length along the transect, and the y-axis is the height of the plant individuals (see also Figure $2 \mathrm{~b}$ in main text).

We run the same analysis as before to obtain the null distribution of overlap between the two species (Figure S9).

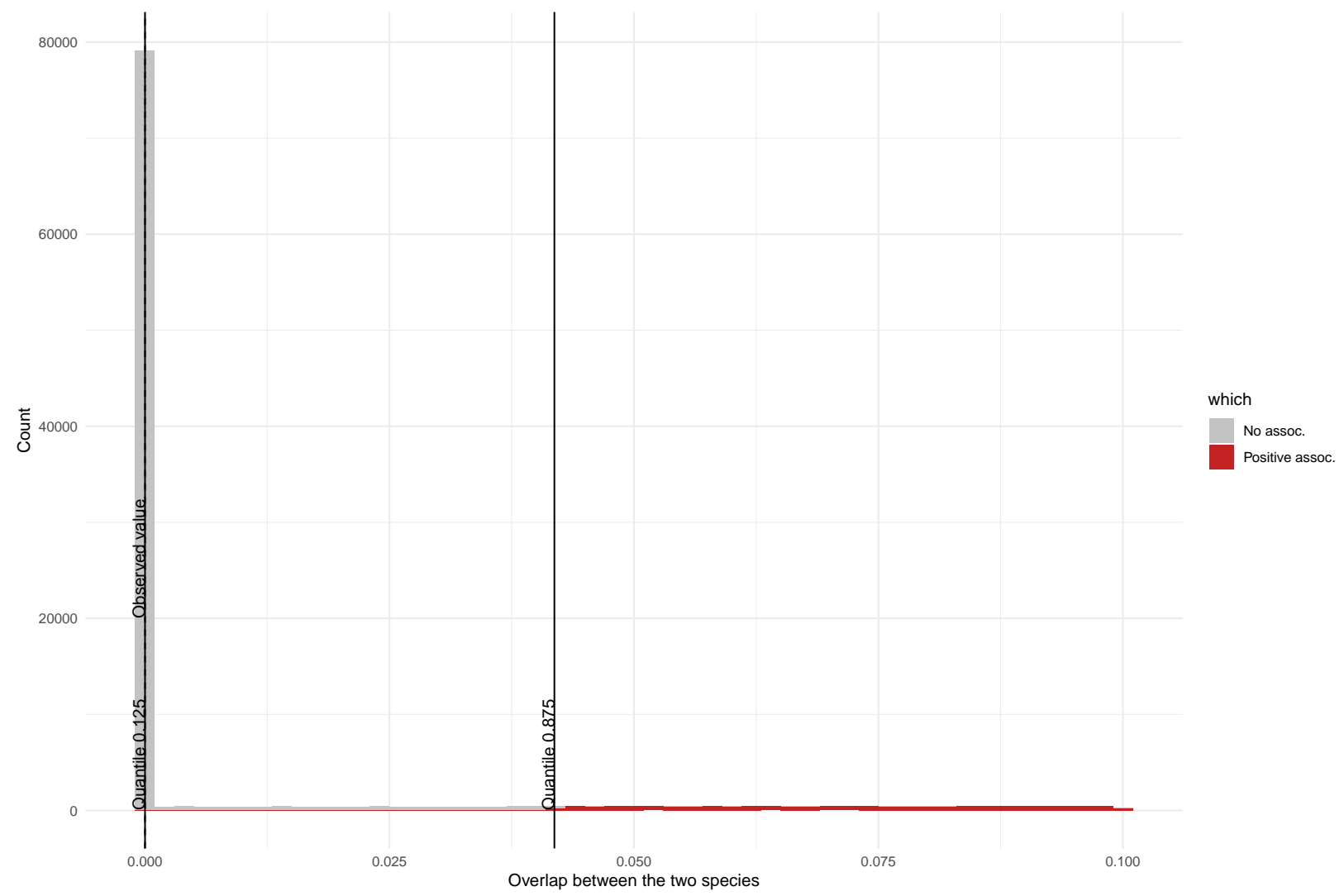

Figure S9 - Null distribution of overlap for a transect with a pair of species with low cover (10\%). The continuous lines indicate the quantiles above or under which a significant positive or negative association is retained, respectively (for $\alpha=0.25$ ). The dashed line indicates the observed value. Note that the observed value and the lower quantile lines are superposed. 
This distribution is heavily skewed, and has a high excess of zeroes (no overlap between the two species). As a result, the lower cutoff is zero (i.e. the $12.5 \%$ quantile is zero), which is also the natural bound for the metric of overlap, which cannot be negative. As a result, such two rare species cannot exhibit an overlap lower than the cutoff, and thus cannot exhibit a negative association, regardless of their ability to exclude spatially other species.

We can produce this null distribution of overlaps for different values of cover of the two species and track when the lower quantile of the null distribution is zero. Simulations show that for the case above, the lower quantile of the null distribution is zero up to the cover of $41 \%$. This means that two species with a cover below this number will never exhibit a negative association for statistical reasons.

This asymmetrical detection of associations has a very strong effect on the estimates of the community scale metrics (e.g. the total number of negative links), as natural communities have a few abundant species and a lot of rare ones. To correctly interpret trends along gradients where species abundances change, it is thus necessary to compare, not the raw values of community metrics, but how much they deviate to what is expected given the distribution of abundances (see Methods in the main text).

\section{References}

Bürkner, Paul-Christian. 2017. "brms: An R Package for Bayesian Multilevel Models Using Stan." Journal of Statistical Software, 80(1), 1-28. doi:10.18637/jss.v080.i01

Dureau, Rémi. 1998. "Conduite pastorale et répartition de l'avifaune nicheuse des coussouls. Patrimoine naturel et pratiques pastorales en Crau - Rapport du programme LIFE ACE Crau". Patrimoine naturel et pratiques pastorales en Crau - Rapport du programme LIFE ACE Crau.

Gomila, Hervé. 1987. "Relations Sol-Végétation Dans La Plain de La Crau." DEA d'Ecologie Méditerranéenne. Université de droit, d'économie et des sciences d'Aix-Marseille.

Molinier, René, and Gabriel Tallon. 1950. "La végétation de la Crau." Revue générale de botanique, no. 56: 525-40.

Selbie, Diana R., Laura E. Buckthought, and Mark A. Shepherd. 2015. "The Challenge of the Urine Patch for Managing Nitrogen in Grazed Pasture Systems." In Advances in Agronomy, 129:229-92. Elsevier. https://doi.org/10.1016/bs.agron.2014.09.004.

Steinauer, E. M., and S. L. Collins. 1995. "Effects of Urine Deposition on Small-Scale Patch Structure in Prairie Vegetation.” Ecology 76 (4): 1195-1205. https://doi.org/10.2307/1940926.

Tatin, Laurent, Axel Wolff, Jean Boutin, Etienne Colliot, and Thierry Dutoit. 2013. Écologie et conservation d'une steppe méditerranéenne la plaine de la Crau. Versailles: Éd. Quae. 